\title{
Regionalização Hidrológica na Bacia do Alto São Francisco a Montante da Barragem de Três Marias, Minas Gerais
}

\author{
Humberto Paulo Euclydes \\ Fundação Rural Mineira - RURALMINAS e Universidade Federal de Viçosa - UFV - Viçosa, MG \\ hpeuclyd@mail.ufo.br
}

\author{
Paulo Afonso Ferreira, Og Arão Vieira Rubert e Ronaldo Medeiros dos Santos \\ Universidade Federal de Viçosa - Viçosa, MG \\ pafonso@mail.ufo.br,ogrubert@mail.ufo.br
}

Recebido: 13/11/00 - revisão: 18/01/01 - aceito: 22/03/01

\begin{abstract}
RESUMO
Este trabalho descreve os estudos realizados para obtenção de metodologia para a estimativa das potencialidades e disponibilidades dos recursos hídricos em qualquer curso d'água da região do Alto São Francisco - MG.

A regionalização das vazões médias, mínimas, máximas e das vazões obtidas da curva de permanência foi desenvolvida sob dois enfoques. O primeiro, denominado Regionalização Hidrológica I/II utilizou a metodologia, segundo a qual, as vazões são regionalizadas com base nas estatísticas dos resultados da aplicação da regressão múltipla das vazões, com as características físicas e climáticas das sub-bacias da região em estudo. O segundo denominado Regionalização Hidrológica II/II, teve como objetivo avaliar as potencialidaes e disponibilidades hídricas a partir da precipitação pluvial espacializada na bacia hidrográfica.

Observando os limites das regiões hidrológicamente homogêneas, verificou-se que os modelos encontrados neste trabalho permitem, em qualquer seção dos cursos d'água da bacia do rio São Francisco a montante da Barragem de Três Marias, estimar: a) vazões específicas mínimas de sete dias de duração, associadas aos períodos de retorno de 2, 5, 10, 20 e 50 anos; b) vazões específicas máximas diárias anuais, associadas aos períodos de retorno de 2, 5, 10, 20, 50, 100 e 500 anos; c) vazão específica média de longo período; d) vazões com permanência de $50 \%$ a $95 \%$; e e) volumes para regularização de vazões.
\end{abstract}

Palavras-chave: regionalização; disponibilidade hídrica; regionalização hidrológica.

\section{INTRODUÇÃO}

Atendendo às metas do projeto HIDROTEC, relativo ao "Desenvolvimento de Tecnologia de Suporte aos Projetos Hidroagrícolas para o Estado de Minas Gerais", e considerando a importância sócio-econômica das regiões compreendidas pela bacia do Alto São Francisco a montante da barragem de Três Marias, este estudo teve como objetivo principal a regionalização das vazões máximas, mínimas, médias de longo período, curvas de permanência e curvas de regularização para a referida região.

Os dados foram processados utilizando-se o software RH versão 3.0 - Regionalização Hidrológica, fruto do convênio Ministério do Meio Ambiente e da Amazônia Legal - Secretaria de Recursos Hídricos/Fundação Rural Mineira - RURALMINAS /Universidade Federal de Viçosa.

\section{CARACTERÍSTICAS FISIOGRÁFICAS DA BACIA DO ALTO SÃO FRANCISCO}

A região está localizada entre os paralelos $18^{\circ}$ e $21^{\circ}$ de latitude sul e os meridianos $43^{\circ} 30^{\prime}$ e $46^{\circ} 40^{\prime}$ de longitude oeste na região central de Minas Gerais. Possui uma área de aproximadamente $51.000 \mathrm{~km}^{2}$, abrangendo cerca de 106 municípios.

$\mathrm{O}$ rio São Francisco nasce na serra da Canastra, município de São Roque de Minas em Minas Gerais, a $1.460 \mathrm{~m}$ de altitude. Após percorrer $570 \mathrm{~km}$ é barrado formando o reservatório de Três Marias.

A sub-bacia 40 corresponde à área de drenagem do Alto São Francisco, que compreende as nascentes dos rios São Francisco, Pará, Paraopeba, Indaiá, Borrachudo e seus afluentes até a barragem de Três Marias da CEMIG. 
O relevo na região em estudo é caracterizado por planos, depressões e áreas dissecadas resultantes predominantemente da alternância de atuação de processos morfoclimáticos associados ao condicionamento geológico. As unidades geomorfológicas existentes são as seguintes: Planalto Dissecado do Centro-Sul e Leste de Minas; Depressão São Franciscana; Planalto do São Francisco.

Com relação a geologia a região em estudo estrutura-se essencialmente sobre rochas de idade pré-cambriana, desde arqueanas até proterozóicas superiores. Apenas uma pequena parcela drena unidades mesozóicas da serra Mata da Corda.

A vegetação nativa da região do Alto São Francisco é constituída predominantemente pelo cerrado, que se estendia originalmente por quase toda sub-bacia. Este tipo de vegetação é característico de regiões de clima semi-úmido, constituindose principalmente de gramíneas, arbustos e árvores de médio porte, tendo como principal característica os troncos e galhos retorcidos e as folhas espessas e coriáceas.

Quanto ao clima, a região em estudo apresenta temperatura média anual variando entre $19^{\circ} \mathrm{e}$ $23^{\circ} \mathrm{C}$, sendo que as menores temperaturas são encontradas ao sul da bacia devido à influência orográfica, ocorrendo um aumento gradativo assim que se alcançam as latitudes mais baixas.

A região do Alto São Francisco abrange 106 municípios, localizados total ou parcialmente dentro da sub-bacia. Estes municípios possuem cerca de 2,5 milhões de habitantes, segundo estimativa do IBGE para 1993.

A densidade populacional da sub-bacia 40 é muito variada. A região sudeste, onde se encontra a $\mathrm{RMBH}$, é a mais populosa e povoada, com mais de $100 \mathrm{hab} . / \mathrm{km}^{2}$, correspondendo aos trechos alto e médio Paraopeba e médio Pará. As regiões oeste e norte da sub-bacia possuem densidades mais baixas variando entre 2 a $25 \mathrm{hab} . / \mathrm{km}^{2}$. Estas áreas correspondem às nascentes do São Francisco, bacias do rio Indaiá e Borrachudo e no entorno do reservatório de Três Marias. Na região central da subbacia em volta do rio São Francisco a densidade demográfica varia entre 25 a 100 hab. $/ \mathrm{km}^{2}$.

Quanto a hidrografia, os principais afluentes do rio São Francisco na sub-bacia 40 são, pela margem direita, rio São Miguel, Ribeirão Santana, rio Pará, rio Paraopeba e Ribeirão da Extrema Grande; e pela margem esquerda, rio Samburá, rio Ajudas, rio Bambuí, Ribeirão Jorge Grande, rio Marmelada, rio Indaiá e rio Borrachudo.
No sentido de se obter outros estudos temáticos com objetivos afins, que integram o projeto HIDROTEC relativo a quantificação de recursos hídricos, a regionalização das vazões foi desenvolvida sob dois enfoques.

O primeiro, denomimado Regionalização Hidrológica I/II, utiliza a metodologia segundo a qual as vazões são regionalizadas com base nas estatísticas dos resultados da aplicação da regressão múltipla das vazões com as características físicas e climáticas das sub-bacias da região em estudo.

$\mathrm{O}$ segundo, denominado Regionalização $\mathrm{Hi}$ drológica II/II, corresponde a uma tentativa de correlação entre a vazão média de longo período e as precipitações anuais, tendo como finalidade avaliar as disponibilidades e as potencialidades hídricas a partir da precipitação média anual espacializada na bacia hidrográfica.

\section{REGIONALIZAÇÃO HIDROLÓGICA I/II}

A metodologia utilizada neste procedimento para vazões máximas e mínimas, consiste basicamente na utilização de dois critérios para identificar as regiões hidrologicamente homogêneas, para as vazões estudadas em uma bacia hidrográfica, e na aplicação de dois métodos de regionalização de vazão. Já a vazão média de longo período, por ser caracterizada como a média das vazões médias diárias anuais, é regionalizada sem se considerar o nível de risco.

Esta metodologia já foi utilizada nos estudos desenvolvidos no Estado de Minas Gerais nas sub-bacias dos rios: Juatuba $\left(443 \mathrm{~km}^{2}\right)$, Verde Grande $\left(30.474 \mathrm{~km}^{2}\right)$, Pardo $\left(12.890 \mathrm{~km}^{2}\right)$, Jequitaí $\left(4.900 \mathrm{~km}^{2}\right)$, Jequitinhonha $\left(67.769 \mathrm{~km}^{2}\right)$, Doce $\left(57.528 \mathrm{~km}^{2}\right)$, Paracatu $\left(45.600 \mathrm{~km}^{2}\right)$ e Paraopeba $\left(13.643 \mathrm{~km}^{2}\right)$, totalizando uma área de $233.247 \mathrm{~km}^{2}$, representando aproximadamente $40 \%$ da área do Estado de Minas Gerais (outubro/99).

O trabalho foi realizado em etapas. A primeira etapa compreendeu a seleção das estações e a análise dos dados descritivos, hidrológicos e físicos da bacia.

Pelo inventário das estações fluviométricas e pluviométricas, editado pelo Departamento Nacional de Água e Energia Elétrica (DNAEE), foram identificadas 96 estações fluviométricas e 120 estações pluviométricas já extintas, bem como aquelas ainda em operação, na bacia do rio São Francisco a montante da barragem de Três Marias. 
Utilizando-se de cartas geográficas na escala de 1:250.000 e diagramas de barra de estações fluvio-pluviométricas, as estações passaram por um processo de pré-seleção observando-se principalmente a sua localização em relação à rede fluvial, período de operação e qualidade das observações. Verificou-se que a maioria das estações fluviométricas localiza-se ao longo dos rios principais e poucas estão em bacias pequenas. Esta análise permitiu selecionar nas séries históricas um período comum de observações, denominado período-base, abrangendo os anos de 1964 a 1992, ou seja 29 anos.

Foram selecionadas 33 estações fluviométricas e 46 estações pluviométricas.

Posteriormente procedeu-se ao preenchimento das falhas e extensão das séries fluviopluviométricas no período selecionado.

As localizações das estações fluviométricas e pluviométricas são apresentadas na Figura 1. De posse das cartas geográficas na escala de 1:250.000, determinaram-se as características físicas das subbacias hidrográficas tais como a área, densidade de drenagem, comprimento e declividade do curso d'água principal.

As denominações e as características físicas das sub-bacias selecionadas são apresentadas na Tabela 1.

Na regionalização da vazão máxima foram empregados os valores máximos diários anuais das séries históricas fluviais. Para os dados pluviais, foram utilizados os valores correspondentes ao semestre mais chuvoso de cada ano.

$\mathrm{Na}$ regionalização de vazão mínima foram empregados os valores mínimos anuais de sete dias de duração das séries fluviométricas. Para os dados de pluviometria, foram utilizados os valores correspondentes à média do total anual. $\mathrm{Na}$ regionalização da vazão média de longo período foram utilizados os valores correspondentes à média das vazões médias diárias anuais, enquanto para os dados de pluviometria foram utilizados os valores correspondentes à média do total anual.

A segunda etapa correspondeu ao cálculo da precipitação média nas sub-bacias, calculada por meio do polígono de Thiessen.

Este método atribui um fator de peso aos totais precipitados em cada pluviometro, proporcionais à área de influência de cada um. As áreas de influência (pesos) são determinadas no mapa da bacia contendo as estações, unindo-se os pontos adjacentes por linhas retas e, em seguida, traçandose as mediatrizes dessas retas formando polígonos.
Os lados dos polígonos são os limites das áreas de influência de cada estação.

A precipitação média é calculada pela média ponderada, entre a precipitação Pi de cada estação e o peso a ela atribuído Ai que é área de influência de Pi, ou seja:

$$
\mathrm{Pm}=\frac{\sum(\mathrm{PiAi})}{\sum \mathrm{Ai}}
$$

em que: Pi - precipitação pluviométrica de cada estação; $\mathrm{Ai}$ - área de influência do Pi.

$\mathrm{Na}$ versão 3.0 do $\mathrm{RH}$ foi desenvolvido um módulo para aplicação deste método. São exigidos como dados de entrada as coordenadas geográficas dos vértices dos polígonos que definem a bacia principal e todas as sub-bacias, além das coordenadas geográficas e do valor da precipitação média (no período considerado) de cada estação pluviométrica.

A terceira etapa compreendeu a identificação das regiões hidrologicamente homogêneas.

Neste trabalho optou-se pela adoção de dois critérios para definição de regiões hidrologicamente homogêneas:

Critério 1 - Baseado na análise da distribuição de freqüência em papel probabilístico das vazões adimensionalizadas de cada estação.

O princípio em que se baseia este critério é que as distribuições de freqüências das vazões médias, máximas e mínimas das estações em uma região hidrologicamente homogênea são idênticas a menos de um fator de escala. Esse fator de escala é a média das séries de vazões consideradas. Essa característica permite que, ao se obter séries transformadas de vazões, através da divisão dos seus valores pelas respectivas médias, as distribuições de freqüência dessas séries transformadas sejam idênticas.

As distribuições de freqüência das séries de vazões podem ser representadas por distribuições teóricas de probabilidades, notadamente as distribuições normal, log-normal, Gumbel e Weibull. Essas características permitem que o gráfico formado pelos pontos representativos dos valores de vazões, anotados em papel probabilístico adequado, seja o de uma linha reta. Desta forma, a equação da função distribuição de freqüências pode ser obtida pelo método dos mínimos quadrados. 


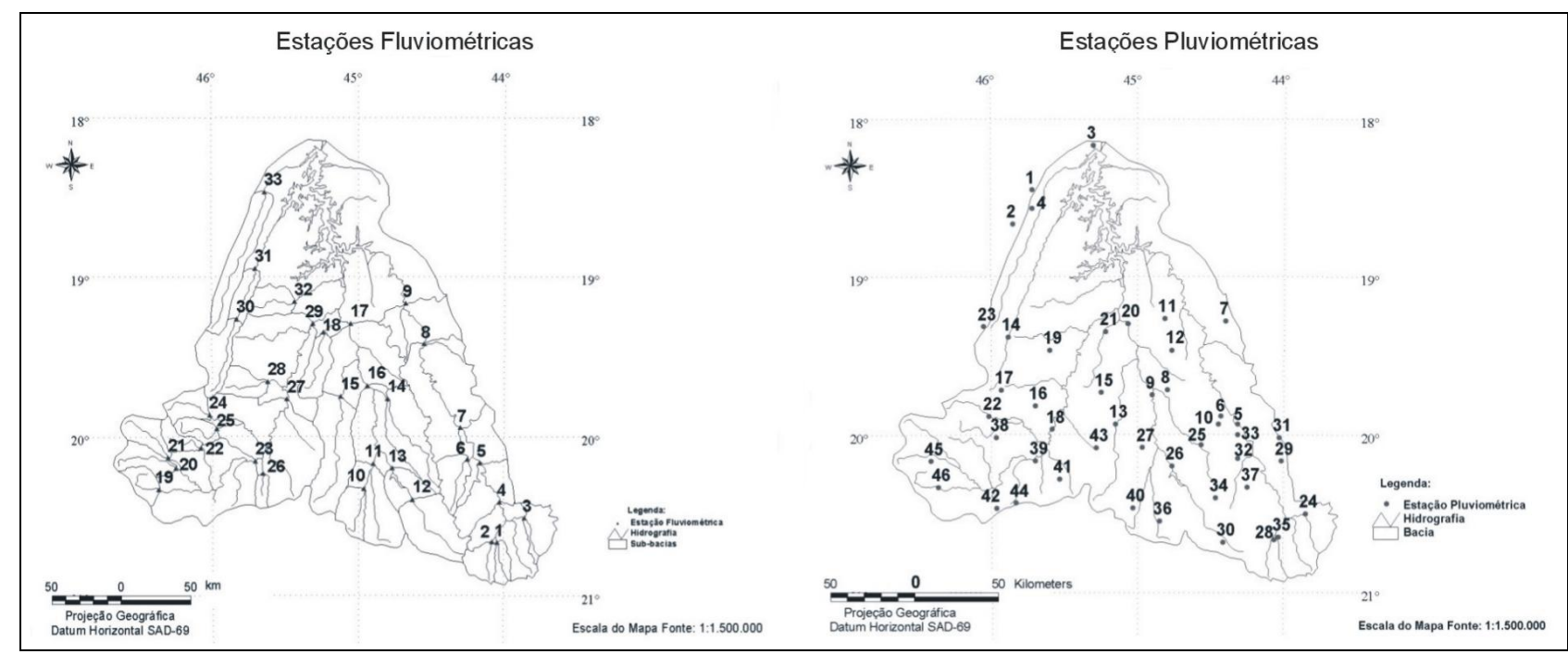

Figura 1. Estações fluviométricas e pluviométricas na bacia do São Francisco a montante da Barragem de Três Marias.

Tabela 1. Nome das sub-bacias e dos cursos d'água, área de drenagem (A), comprimento do curso d'água principal (L), densidade de drenagem (Dd) e declividade do curso d'água principal (Dc).

\begin{tabular}{|c|c|c|c|c|c|}
\hline Sub-bacias & Curso d'água & $\mathrm{A}\left(\mathrm{km}^{2}\right)$ & $\mathrm{L}(\mathrm{km})$ & $\mathrm{Dd}\left(\mathrm{km} / \mathrm{km}^{2}\right)$ & $\mathrm{Dc}(\mathrm{m} / \mathrm{km})$ \\
\hline U.J. Ribeiro & Camapua & 259 & 35,00 & 0,81 & 1,70 \\
\hline E.Rios Minas & R. Brumaco & 469 & 40,00 & 0,72 & 5,50 \\
\hline Congonhas & Maranhão & 613 & 35,00 & 0,68 & 4,80 \\
\hline Belo Vale & Paraopeba & 2690 & 100,00 & 0,73 & 1,80 \\
\hline A. Flores & Paraopeba & 3945 & 160,00 & 0,70 & 1,30 \\
\hline C.do Itagua & R. Manso & 649 & 55,00 & 0,82 & 5,10 \\
\hline P.N. Paraopeba & Paraopeba & 5663 & 210,00 & 0,75 & 1,20 \\
\hline Pte. Taquara & Paraopeba & 8571 & 320,00 & 0,69 & 0,80 \\
\hline P. Mesquita & Paraopeba & 10300 & 390,00 & 0,71 & 0,70 \\
\hline Marilândia & Itapecerica & 533 & 34,75 & 0,66 & 3,80 \\
\hline Pari & Itapecerica & 1849 & 67,13 & 0,61 & 3,60 \\
\hline Pte. do Vilela & R. Para & 1620 & 66,00 & 0,72 & 5,40 \\
\hline C. Cajuru & R. Para & 2402 & 107,75 & 0,65 & 3,50 \\
\hline Jaguaruna-J & São João & 1543 & 93,00 & 0,38 & 4,50 \\
\hline E.A.da Silveira & R. Lambari & 1803 & 114,00 & 0,63 & 2,60 \\
\hline V. da Taipa & R. Para & 7109 & 211,75 & 0,64 & 2,20 \\
\hline Porto Pará & R. Para & 12300 & 270,75 & 0,55 & 1,90 \\
\hline M. Campos & R. Picão & 715 & 56,00 & 0,55 & 1,10 \\
\hline V. Bonita & R. São Francisco & 350 & 38,50 & 0,53 & 15,60 \\
\hline F. da Barra & R. Santo Antônio & 743 & 55,30 & 0,68 & 6,70 \\
\hline F. Sambura & R. Sambura & 738 & 58,00 & 0,57 & 6,20 \\
\hline Faz. Ajudas & R. Ajudas & 327 & 50,00 & 0,55 & 5,20 \\
\hline Iguatama & R. São Francisco & 4846 & 145,50 & 0,68 & 3,50 \\
\hline Tapiraí-Jus & R. Perdição & 543 & 48,00 & 0,60 & 10,90 \\
\hline M.B.Sucesso & R. Bambuí & 269 & 48,00 & 0,77 & 7,50 \\
\hline Calciolândia & São Miguel & 276 & 32,50 & 0,45 & 5,00 \\
\hline Ponte Chumbo & R. São Francisco & 9255 & 228,60 & 0,62 & 0,90 \\
\hline Taquaral & R. Jorge Grande & 623 & 60,00 & 0,57 & 3,20 \\
\hline Porto Andorinhas & R. São Francisco & 13087 & 335,85 & 0,62 & 0,50 \\
\hline B. Funchal & R. Indaia & 881 & 48,90 & 0,68 & 6,90 \\
\hline F. B. Jardim & R. Indaia & 1708 & 147,25 & 0,56 & 2,00 \\
\hline Abaeté & Marmelada & 466 & 54,00 & 0,63 & 3,10 \\
\hline F. São Félix & Borrachudo & 905 & 125,38 & 0,50 & 2,40 \\
\hline
\end{tabular}


Critério 2 - critério estatístico baseado na análise do ajuste do modelo de regressão múltipla das vazões médias com as características físicas e climáticas das subbacias

Para a definição das regiões hidrologicamente homogêneas, são analisados os coeficientes da regressão, a tendência e a classificação dos resíduos padronizados e o erro percentual entre os valores das vazões observadas e as estimadas pelo modelo.

A combinação de estações que apresentar o melhor ajustamento, provavelmente, deverá estar em uma região hidrologicamente homogênea.

Finalmente, se os dois critérios apresentarem bons resultados a região é definida como hidrologicamente homogênea para as vazões estudadas, se não, há necessidade de subdividir a região e reiniciar o processo novamente.

A quarta etapa comprendeu a aplicação de dois métodos de regionalização de vazão, quais sejam:

Método 1 - Regionaliza a vazão com determinado risco - Consiste em ajustar distribuições teóricas de probabilidades às séries históricas de vazões de cada estação para diferentes períodos de retorno e a seguir aplicar regressão múltipla entre estas vazões e as características físicas e climáticas das sub-bacias (Euclydes, 1992).

Várias distribuições tem sido propostas para representar os eventos máximos e mínimos. Neste trabalho foram selecionadas para representar os eventos máximos as distribuições de Gumbel, Log-normal a dois e três parâmetros, Pearson tipo III e log-Pearson tipo III, enquanto para os eventos mínimos foram utilizadas a Log-normal a três parâmetros, Pearson tipo III, log-Pearson tipo III e Weibull, por terem sido as mais empregadas (Kite, 1978; Maione, 1977; Lettenmair e Burges, 1982; Cruff e Rantz, 1965).

Ao se aplicar uma distribuição de probabilidade como modelo para descrever as vazões de um curso d'água deve-se testar a adequação deste procedimento, ou seja, verificar a boa ou má aderência dos dados da amostra ao modelo. Esta verificação é realizada por meio de testes de aderência como o teste do qui-quadrado, método de Kolmogorov-Smirnov e gráficamente.

Neste trabalho é utilizado o método de Kolmogorov-Smirnov para testar os ajustes dos modelos probabilísticos.
Método 2 - Regionaliza uma curva adimensional de freqüência e o fator de adimensionalização - Consiste em adimensionalizar as curvas individuais de probabilidade, com base em seu valor médio, e estabelecer uma curva adimensional regional média das estações com a mesma tendência (Tucci, 1993).

A curva adimensional regional de freqüência é expressa por:

$$
\mathrm{F}_{1}\left(\frac{\mathrm{Q}_{\mathrm{T}}}{\mathrm{Q}_{\mathrm{m}}}\right)=\frac{1}{\mathrm{~T}}
$$

onde $\mathrm{Q}_{\mathrm{T}}$ é a vazão estimada para período de retorno $\mathrm{T}$ e $\mathrm{Q}_{\mathrm{m}}$ é o valor médio.

O valor médio é regionalizado em função das características físicas e climáticas das subbacias, através de uma equação de regressão múltipla, expressa por:

$$
\mathrm{Q}_{\mathrm{m}}=\mathrm{F}_{2}(\mathrm{~A}, \mathrm{~L}, \mathrm{Dd}, \ldots)
$$

em que $F_{2}(A, L, D d, .$.$) = equação de regressão múl-$ tipla.

A curva adimensional regional de freqüência é determinada ajustando-se a equação da reta de regressão da forma $\mathrm{y}=\mathrm{a}+\mathrm{bx}$ às vazões adimensionalizadas, plotadas em papel probabilístico, das estações pertencentes a região definida como hidrologicamente homogênea. Os parâmetros são estimados pelo método gráfico e a verificação do ajuste é pelo método do mínimos quadrados. São aplicado limites de confiança de $95 \%$ e o erro padrão de estimativa de freqüências é determinado com o auxilio da reta regional.

Conhecendo-se a equação de regressão múltipla da vazão média e a relação $\mathrm{Q}_{\mathrm{T}} / \mathrm{Q}_{\mathrm{m}}$, determinada com o auxílio da curva de freqüência regional, Equação (2), a equação de vazão máxima ou mínima $\mathrm{Q}_{\mathrm{T}}$, estimada para um período de retorno T, é:

$$
\mathrm{Q}_{(\mathrm{T})}=\left(\frac{\mathrm{Q}_{\mathrm{T}}}{\mathrm{Q}_{\mathrm{m}}}\right)_{\mathrm{R}} \mathrm{Q}_{\mathrm{mr}}
$$

em que: $\left(Q_{\mathrm{T}} / \mathrm{Q}_{\mathrm{m}}\right)_{\mathrm{R}}$ - termo adimensional da curva de freqüência regional para período de retorno $\mathrm{T}$; $\mathrm{Q}_{\mathrm{m}}$ - média aritmética das vazões máximas ou mínimas cada estação; $Q_{\mathrm{mr}}$ - vazão média-máxima ou 
média mínima estimada pela equação de regressão múltipla.

Objetivando apresentar uma visualização da distribuição espacial das vazões, de modo a permitir ao usuário uma primeira informação sobre os recursos hídricos da bacia, procedeu-se a um mapeamento das vazões específicas média de longo período, minima de sete dias de duração $(T=10$ anos), máxima diária anual ( $\mathrm{T}=50$ anos), na quinta e última etapa.

\section{Metodologia de regionalização da curva de permanência}

A curva de permanência indica a porcentagem de tempo em que um determinado valor de vazão foi igualado ou ultrapassado durante um período de observações. Ela permite visualizar, de imediato, a potencialidade natural do curso d'água, destacando-se a vazão mínima e o grau de permanência para qualquer valor da vazão.

Além dos resultados diretos que fornece para o estudo do aproveitamento das disponibilidades do curso d'água, as curvas de permanência constituem um instrumento valioso de comparação entre as características distintas das bacias hidrográficas, colocando em evidência os efeitos do relevo, da vegetação e uso da terra e da precipitação, sobre a distribuição das vazões.

A curva de permanência pode ser estabelecida baseando-se em valores diários, semanais ou mensais. Esta função hidrológica é utilizada em estudo hidrelétrico, navegação, qualidade da água dentre outros. Por exemplo, em sistemas de captação a fio d'água, isto é, sem reservatório de acumulação, usualmente considera vazões com intervalo diário e $95 \%$ de permanência.

A metodologia adotada neste estudo para a determinação da curva de permanência utiliza o método interpolativo. A estimativa da curva de permanência consistiu em estabelecer 50 intervalos de classes para as vazões diárias. Devido à grande variação de magnitude das vazões envolvidas a sub-divisão de cada intervalo foi baseada em escala logarítmica. A amplitude de cada intervalo foi calculada empregando:

$$
\mathrm{d}=[\ln (\mathrm{Qmx})-\ln (\mathrm{Qmi})] / 50
$$

onde Qmx é a vazão máxima da série e Qmi é a vazão mínima da série.
Os limites inferiores dos intervalos foram calculados usando:

$$
Q j=\operatorname{EXP}[Q m i+(j-1) d]
$$

onde Qj é o limite inferior do intervalo j.

A freqüência (fi) de cada intervalo é obtida contando o número de vazões da série que cai no intervalo. Acumulando os valores de fi no sentido da maior vazão para a menor, obtém-se os valores di de permanência. A probabilidade de uma vazão Q ser maior ou igual a Qi é:

$$
\mathrm{P}_{\mathrm{i}}=\frac{\mathrm{di}}{\mathrm{NV}} \cdot 100
$$

onde Nv é o número total de valores.

A regionalização das curvas de permanência consistiu em aplicar regressão múltipla da vazão para as probabilidades selecionadas com as características físicas e climáticas das sub-bacias.

A definição das regiões hidrologicamente homogêneas foi baseada na análise do ajuste do modelo de regressão múltipla das vazões para as probabilidades de 50 a $95 \%$ com as características físicas e climáticas das sub-bacias. Na definição das regiões hidrologicamente homogêneas, foram analisadas as significâncias dos coeficientes da regressão (teste T de Student, coeficientes de correlação e correlação ajustado, erro padrão fatorial, coeficiente de variação e teste F), a tendência e a classificação dos resíduos padronizados e o erro percentual entre os valores das vazões observadas e as estimadas pelo modelo.

\section{Metodologia de regionalização de curvas de regularização}

A regionalização das curvas de regularização permite a primeira estimativa da capacidade de regularização de vazões em locais sem dados. Este tipo de informação é importante para estudos de planejamento e no dimensionamento de projetos de pequena escala. Neste caso, ficam mantidas as limitações de uma demanda constante e o uso de uma estimativa da evaporação.

$\mathrm{O}$ volume de regularização com base nos valores seqüenciais da série histórica pode ser determinado por métodos clássicos, como o da curva de massa das vazões ou diagrama de Rippl. 
Lanna (1993), apresenta diversos métodos para dimensionamento de reservatório. $\mathrm{O}$ "método da curva de diferenças acumuladas" originalmente desenvolvido como método gráfico, mas podendo ser também empregado de forma computacional, tem por objetivo a determinação do volume de armazenamento necessário num reservatório para garantir determinada descarga regularizada constante, durante todo o período da série histórica.

Desta forma, como a demanda é constante ao longo do tempo ela será notada por X. O princípio de conservação de massa permite escrever:

$$
\mathrm{S}_{0}+\sum_{\mathrm{t}=1}^{\mathrm{N}} \mathrm{q}_{\mathrm{t}}=\mathrm{N} \quad \mathrm{X}+\mathrm{S}_{\mathrm{f}}
$$

ou seja, o armazenamento inicial no açude $\left(\mathrm{S}_{0}\right)$ somado aos deflúvios afluentes ao açude durante um período de $\mathrm{N}$ intervalos de tempo $\left(\mathrm{q}_{\mathrm{t}}\right)$, deve ser igual à soma das descargas retiradas do açude neste mesmo período, dada pelo produto (N.X), mais o armazenamento final $\left(\mathrm{S}_{\mathrm{f}}\right)$. Supondo-se que o armazenamento inicial é idêntico ao final, ou que a diferença entre eles é pequena diante da soma das afluências, a Equação (8) simplifica-se:

$$
\sum_{t=1}^{N} q_{t}=N \cdot X
$$

e a descarga máxima atingível, nessas circunstâncias, é:

$$
X=\sum_{t=1}^{N} q_{t} / N
$$

Supondo-se ainda, que o açude tenha capacidade útil infinita, os armazenamentos em qualquer intervalo de tempo $t$ serão dados por:

$$
\mathrm{S}(\mathrm{t})=\mathrm{S}_{0}+\sum_{\mathrm{i}=1}^{\mathrm{t}} \mathrm{q}_{\mathrm{i}}-\mathrm{t} \mathrm{X}
$$

As diferenças acumuladas obtidas pela Equação (11) mostram os acréscimos ou decréscimos, dos armazenamentos no açude.

Simulando a Equação (11) para várias demandas obtem-se a relação entre volume e vazão, ou seja:

$$
V=f 1(q)
$$

onde $\mathrm{V}$ = volume; e q = vazão.
Modificando as variáveis envolvidas para:

$$
\begin{gathered}
\alpha=\mathrm{V} /\left(\mathrm{Q}_{\mathrm{mlp}} 1 \text { ano }\right) \\
\beta=\mathrm{q} / \mathrm{Q}_{\mathrm{mlp}}
\end{gathered}
$$

onde $\mathrm{Q}_{\mathrm{mlp}}=$ vazão média de longo período.

A função da Equação (12) resulta numa função adimensional do tipo:

$$
\alpha=\mathrm{f} 2(\beta)
$$

Com base nos valores obtidos da simulação pode-se ajustar uma função do tipo:

$$
\alpha=\mathrm{a} \beta^{\mathrm{b}}
$$

Os valores dos coeficientes da regressão a e b são obtidos por mínimos quadrados.

Considerando que as curvas adimensionais da Equação (16) são obtidas para cada estação, pode-se verificar a possibilidade de que estações de bacias com características semelhantes tenham a mesma tendência, já que as vazões mensais, que são as variáveis do processo, podem ser correlacionáveis.

A definição das regiões hidrologicamente homogêneas será baseada no coeficiente de determinação do ajustamento da curva regional, e nos valores do coeficiente de regressão " $b$ " obtidos no ajustamento da curva vazão versus volume. As estações que apresentarem altos valores do coeficiente de determinação da curva regional e valores próximos do coeficiente " $b$ ", deverão estar em uma região que, para efeitos de estudo, provavelmente será hidrologicamente homogênea.

\section{Uso das curvas para estimativa do volume}

A estimativa do volume necessário à regularização da vazão, é efetuada conforme os passos:

1. Estime a vazão média de longo período empregando o modelo de regressão múltipla da vazão média de longo período, ajustado para a bacia;

2. sendo $q$ a demanda desejada e $\mathrm{Q}_{\mathrm{mlp}}$ a vazão média de longo período da região, calcule $\mathrm{m}=\left(\mathrm{q} / \mathrm{Q}_{\mathrm{mlp}}\right) \cdot 100$;

3. substitua o valor calculado no item anterior na equação da curva adimensional da regi- 
ão em que se encontra a bacia, obtendo o valor de $\mathrm{r}$, conforme:

$$
\mathrm{r}=\left(\mathrm{V} / \mathrm{Q}_{\mathrm{mlp}} \cdot \mathrm{ano}\right) \cdot 100
$$

4. o volume é obtido por:

$$
\mathrm{V}=0,3154 \cdot \mathrm{r} \cdot \mathrm{Q}_{\mathrm{mlp}}\left(10^{6} \mathrm{~m}^{3}\right)
$$

Para considerar a evaporação, Tucci (1993) sugere uma metodologia simplificada, considerando-a como sendo uma demanda adicional, obtida por:

$$
\text { me }=0,00317 \text { E.A } / Q_{m l p}
$$

onde E é a evaporação total média anual em mm; A a área do reservatório para $2 / 3$ do volume útil, em $\mathrm{km}^{2}$.

A demanda adicional total, neste caso será:

$$
\mathrm{m}^{*}=\mathrm{me}+\mathrm{m}
$$

\section{RESULTADOS E DISCUSSÃO}

\section{Regionalização das vazões médias de longo período, mínimas, máximas e da curva de permanência - Regionalização hidrológica I/II}

\section{Regionalização da vazão média de longo pe-} ríodo - De posse dos coeficientes de ajustamento dos diversos ajustes testados e das características climáticas das trinta e três sub-bacias, definiram-se três regiões homogêneas para as vazões estudadas, as quais estão localizadas no mapa da Figura 2.

Os modelos selecionados com os respectivos coeficientes de ajustamento da vazão média de longo período (Qmlp) em $\mathrm{m}^{3} / \mathrm{s}$, para as regiões I, II e III se encontram na Tabela 2 .

Observa-se que os ajustamentos dos modelos de vazão (Qmlp) para as regiões I, II e III podem ser considerados exelentes do ponto de vista dos coeficientes de ajustamento.

Regionalização da vazão mínima - De posse dos coeficientes de melhor ajustamento e das características climáticas das trinta e três sub-bacias, definiram-se três regiões homogêneas para as vazões mínimas, as quais estão apresentadas no mapa da Figura 2.

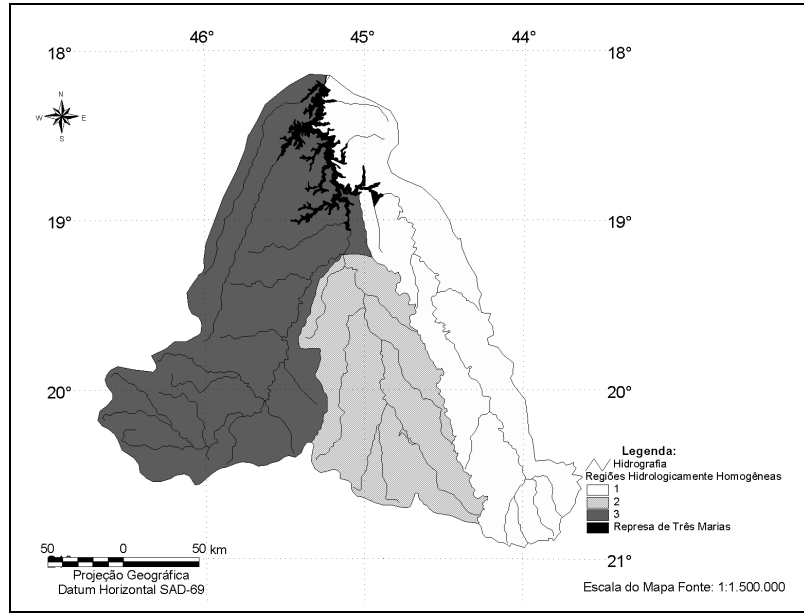

Figura 2. Regiões hidrológicamente homogêneas para vazão média de longo período.

Os resultados da aplicação dos dois métodos preconizados na metodologia, indicaram o método II para representar as vazões mínimas, por apresentar melhor ajustamento e menor número de variáveis independentes nos modelos. Os resultados da aplicação do método II para vazões mínimas de sete dias de duração e período de retorno de 10 anos são apresentados na Tabela 3. Nesta observase que o ajustamento do modelo de regressão múltipla da vazão média mínima (y) apresentou resultados que podem ser considerados de excelente a bom relativamente aos parâmetros estatísticos $\mathrm{R}^{2}$; $\mathrm{R}^{2} \mathrm{a} ; \mathrm{Ep} ; \mathrm{Cv}$ e \%F.

Quanto ao ajustamento do modelo da curva regional $\left(\mathrm{Q}_{10} / \mathrm{Q}_{\mathrm{m}}\right)_{\mathrm{R}}$ os parâmetros de ajustamento da regressão $\left(\mathrm{R}^{2} ; \mathrm{R}^{2} \mathrm{a} ; \mathrm{Ep} ; \mathrm{Cv}\right.$ e $\left.\% \mathrm{~F}\right)$ mostram resultados que podem ser considerados aceitáveis.

A Tabela 4 apresenta o termo adimensional da curva de probabilidade regional, log-Gumbel $\left(\mathrm{Q}_{10} / \mathrm{Q}_{\mathrm{m}}\right)_{\mathrm{R}}$ nas três regiões hidrológicamente homogêneas, para os períodos de retorno de 2, 5, 10, 20 e 50 anos, com intervalos de confiança de 95 e $99 \%$.

No sentido de uniformizar as equações dos modelos de regressão múltipla foi elaborada a Tabela 5 utilizando os dados das Tabelas 3 e 4 . As equações dos modelos foram obtidas multiplicando-se o intercepto do modelo de regressão múltipla da vazão média mínima (Tabela 3) pelo termo adimensional da curva de probabilidade regional (Tabela 4). A seguir, dividindo-se o produto pela área da bacia (A) obteve-se a vazão específica em $\mathrm{L} / \mathrm{s.} \mathrm{km}^{2}$.

Na execução da regionalização verificou-se que as sub-bacias de Calciolândia, Taquaral e Aba- 
Tabela 2. Modelos selecionados e coeficientes de ajustamento.

\begin{tabular}{lcccrr}
\hline Modelos & $\mathrm{R}^{2}$ & $\mathrm{R}^{2} \mathrm{a}$ & $\mathrm{Ep}$ & $\mathrm{CV}$ & $\% \mathrm{~F}$ \\
\hline Qmlp $_{\mathrm{I}}=$ 0,022.A 0,965 & 0,995 & 0,995 & 1,103 & 2,856 & $2,05 \mathrm{E}-07$ \\
Qmlp $_{\text {II }}=5,399+0,013 . \mathrm{A}$ & 0,999 & 0,988 & 5,364 & 11,209 & $3,00 \mathrm{E}-05$ \\
Qmlp $_{\text {III }}=2,540+0,019 . \mathrm{A}$ & 0,992 & 0,992 & 6,775 & 14,224 & $3,89 \mathrm{E}-13$ \\
\hline
\end{tabular}

Tabela 3. Resultado da aplicação do método II na regionalização da vazão mínima de sete dias de duração e período de retorno de 10 anos $(\mathrm{L} / \mathrm{s})$.

\section{Região - I}

I a) Modelo de regressão múltipla da vazão média mínima $\begin{array}{cccccc}\mathrm{Y}=\mathrm{B} 0{ }^{*} \mathrm{x} 1^{\wedge} \mathrm{B} 1{ }^{*} \times 2^{\wedge} \mathrm{B} 2{ }^{*} \ldots \ldots . *^{*} \times \mathrm{n}^{\wedge} \mathrm{Bn} & \mathrm{R}^{2} & \mathrm{R}^{2} \mathrm{a} & \text { ep } & \mathrm{cV} & \% \mathrm{~F} \\ \mathrm{Q}_{\mathrm{m}}=8,726 . \mathrm{A} 0,935 & 0,99 & 0,99 & 1,14 & 1,44 & 2 \mathrm{E}-6\end{array}$

I b) Modelo da curva regional (log-Gumbel)

\begin{tabular}{cccc}
$\left(\mathrm{Q}_{10} / \mathrm{Q}_{\mathrm{m}}\right)_{\mathrm{R}}$ & $\mathrm{R}^{2}$ & ep & $\% \mathrm{~F}$ \\
0,622 & 0,86 & 0,12 & 0,0 \\
& Região - II & & \\
\hline
\end{tabular}

II a) Modelo de regressão múltipla da vazão média mínima

$\begin{array}{cccccc}\mathrm{Y}=\mathrm{B} 0{ }^{*} \mathrm{x} 1^{\wedge} \mathrm{B} 1{ }^{*} \times 2^{\wedge} \mathrm{B} 2{ }^{*} \ldots \ldots . *^{*} \times \mathrm{n}^{\wedge} \mathrm{Bn} & \mathrm{R}^{2} & \mathrm{R}^{2} \mathrm{a} & \text { ep } & \mathrm{cv} & \% \mathrm{~F} \\ \mathrm{Q}_{\mathrm{m}}=8,488 . \mathrm{A}{ }^{0,945} & 0,94 & 0,93 & 1,29 & 2,75 & 2 \mathrm{E}-3\end{array}$

II b) Modelo da curva regional (log-Gumbel)

$\begin{array}{cccc}\left(\mathrm{Q}_{10} / \mathrm{Q}_{\mathrm{m}}\right)_{\mathrm{R}} & \mathrm{R}^{2} & \text { ep } & \% \mathrm{~F} \\ 0,589 & 0,77 & 0,18 & 2,2 \mathrm{E}-14\end{array}$

Região - III

III a) Modelo de regressão múltipla da vazão média mínima

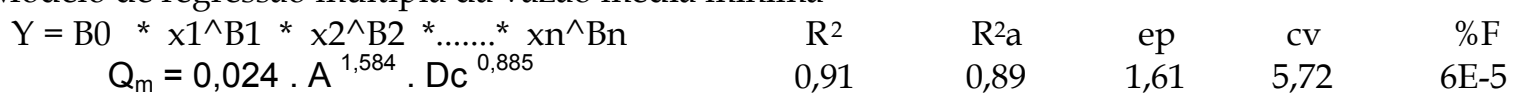

III b) Modelo da curva regional (log-Gumbel)

\begin{tabular}{cccc}
$\left(\mathrm{Q}_{10} / \mathrm{Q}_{\mathrm{m}}\right)_{\mathrm{R}}$ & $\mathrm{R}^{2}$ & $\mathrm{ep}$ & $\% \mathrm{~F}$ \\
0,628 & 0,77 & 0,16 & 0,0 \\
\hline
\end{tabular}

eté apresentavam valores de vazões específicas bem inferiores à média da região. Através da análise dos valores da precipitação média anual (Pma) sobre as referidas sub-bacias verificou-se que os valores das precipitação, nas três sub-bacias, encontravam-se acima da média da região. Descartando, assim, a variável precipitação média por ser uma das principais responsáveis pelos baixos valores encontrados das referidas vazões e partindo do principio de que não tenha ocorrido erros na extrapolação do setor inferior das curvas-chave, acredita-se que esta baixa disponibilidade hídrica possivelmente seja explicada pela pequena profundidade do solo e, ou baixa capacidade de armazenamento dos aquíferos nas referidas bacias.
Regionalização da vazão máxima - De posse dos coeficientes de melhor ajustamento e das características climáticas das trinta e três sub-bacias, definiram-se três regiões homogêneas para as vazões mínimas, as quais estão apresentadas no mapa da Figura 2.

Os resultados da aplicação dos dois métodos preconizados na metodologia, indicaram o método II como o mais representativo das vazões máximas diárias anuais, por resultar em melhor ajustamento e menor número de variáveis independentes nos modelos. Os resultados da aplicação do método II para o período de retorno de 50 anos são apresentados na Tabela 6. Nesta observa-se que o ajustamento do modelo de regressão múltipla da vazão média máxima (y) apresentou resultados que 
Tabela 4. Valores do termo adimensional da curva regional para os períodos de retorno estudados e intervalos de confiança de 95 e $99 \%$.

\begin{tabular}{|c|c|c|c|c|c|}
\hline & 2 & 5 & $\begin{array}{l}\text { dos de } r \\
\quad 10 \\
-\mathrm{I}\end{array}$ & 20 & 50 \\
\hline $\begin{array}{c}\left(\mathrm{Q}_{\mathrm{T}} / \mathrm{Q}_{\mathrm{M}}\right)_{\mathrm{R}} \\
+95 \% \\
-95 \% \\
+99 \% \\
-99 \%\end{array}$ & $\begin{array}{l}0,997 \\
1,316 \\
0,755 \\
1,372 \\
0,724\end{array}$ & $\begin{array}{l}0,751 \\
0,991 \\
0,568 \\
1,034 \\
0,545\end{array}$ & $\begin{array}{l}0,622 \\
0,822 \\
0,471 \\
0,857 \\
0,451\end{array}$ & $\begin{array}{l}0,519 \\
0,687 \\
0,392 \\
0,717 \\
0,376\end{array}$ & $\begin{array}{l}0,411 \\
0,546 \\
0,310 \\
0,570 \\
0,297\end{array}$ \\
\hline \multicolumn{6}{|c|}{ Região - II } \\
\hline $\begin{array}{c}\left(\mathrm{Q}_{\mathrm{T}} / \mathrm{Q}_{\mathrm{M}}\right)_{\mathrm{R}} \\
+95 \% \\
-95 \% \\
+99 \% \\
-99 \%\end{array}$ & $\begin{array}{l}0,988 \\
1,492 \\
0,654 \\
1,588 \\
0,614\end{array}$ & $\begin{array}{l}0,724 \\
1,095 \\
0,479 \\
1,165 \\
0,450\end{array}$ & $\begin{array}{l}0,589 \\
0,893 \\
0,389 \\
0,950 \\
0,366\end{array}$ & $\begin{array}{l}0,484 \\
0,734 \\
0,319 \\
0,782 \\
0,299\end{array}$ & $\begin{array}{l}0,375 \\
0,571 \\
0,246 \\
0,608 \\
0,231\end{array}$ \\
\hline \multicolumn{6}{|c|}{ Região - III } \\
\hline $\begin{array}{c}\left(\mathrm{Q}_{\mathrm{T}} / \mathrm{Q}_{\mathrm{M}}\right)_{\mathrm{R}} \\
+95 \% \\
-95 \% \\
+99 \% \\
-99 \%\end{array}$ & $\begin{array}{l}0,991 \\
1,430 \\
0,687 \\
1,510 \\
0,651\end{array}$ & $\begin{array}{l}0,753 \\
1,086 \\
0,522 \\
1,148 \\
0,494\end{array}$ & $\begin{array}{l}0,628 \\
0,906 \\
0,435 \\
0,958 \\
0,411\end{array}$ & $\begin{array}{l}0,527 \\
0,762 \\
0,365 \\
0,805 \\
0,345\end{array}$ & $\begin{array}{l}0,420 \\
0,609 \\
0,290 \\
0,644 \\
0,275\end{array}$ \\
\hline
\end{tabular}

Tabela 5. Modelos selecionados de vazão específica mínima de sete dias de duração e períodos de retorno de $2,5,10$ e 20 anos $\left(\mathrm{L} / \mathrm{s} . \mathrm{km}^{2}\right)$ nas três regiões.

\begin{tabular}{|c|c|c|}
\hline Período de retorno & $\begin{array}{l}\text { Variáveis } \\
\text { Região - I }\end{array}$ & Modelos selecionados \\
\hline 2 & Área & $\mathrm{Q}=8,700 . \mathrm{A}^{-0,065}$ \\
\hline 5 & Área & $\mathrm{Q}=6,553 . \mathrm{A}^{-0,065}$ \\
\hline 10 & Área & $\mathrm{Q}=5,428 \cdot \mathrm{A}^{-0,065}$ \\
\hline 20 & Área & $\mathrm{Q}=4,529 . \mathrm{A}^{-0,065}$ \\
\hline \multirow[t]{2}{*}{50} & Área & $\widehat{Q}=3,586 \cdot A^{-0,065}$ \\
\hline & \multicolumn{2}{|l|}{ Região - II } \\
\hline 2 & Área & $\mathrm{Q}=8,386 \cdot \mathrm{A}^{-0,055}$ \\
\hline 5 & Área & $\mathrm{Q}=6,145 . \mathrm{A}^{-0,055}$ \\
\hline 10 & Área & $\widehat{\mathrm{Q}}=4,999 . \mathrm{A}^{-0,055}$ \\
\hline 20 & Área & $\mathrm{Q}=4,108 \cdot \mathrm{A}^{-0,055}$ \\
\hline \multirow[t]{2}{*}{50} & Área & $\mathrm{Q}=3,183 . \mathrm{A}^{-0,055}$ \\
\hline & Região - III & \\
\hline 2 & Área, Declividade rio & $q=0,024 . A^{0,584}$. Dc ${ }^{0,885}$ \\
\hline 5 & Área, Declividade rio & $\mathrm{q}=0,018 \cdot \mathrm{A}^{0,584} \cdot$ Dc 0,885 \\
\hline 10 & Área, Declividade rio & $\mathrm{q}=0,015 \cdot \mathrm{A}^{0,584} \cdot \mathrm{Dc}^{0,885}$ \\
\hline 20 & Área, Declividade rio & $q=0,013 \cdot A^{0,584} \cdot D^{0,885}$ \\
\hline 50 & Área, Declividade rio & $\mathrm{q}=0,010 \cdot \mathrm{A}^{0,584} \cdot$ Dc $^{0,885}$ \\
\hline
\end{tabular}


Tabela 6. Resultado da aplicação do método II na regionalização de vazão máxima diária anual com período de retorno de 50 anos $\left(\mathrm{m}^{3} / \mathrm{s}\right)$.

\section{Região - I}

I a) Modelo de regressão múltipla da vazão média máxima (Qmx)

$$
\begin{gathered}
\mathrm{Y}=\mathrm{B} 0{ }^{*}{ }^{*} \mathrm{x} 1^{\wedge} \mathrm{B} 1{ }^{*} \mathrm{x} 2^{\wedge} \mathrm{B} 2{ }^{*} \ldots \ldots . .{ }^{*} \mathrm{xn} \mathrm{n}^{\wedge} \mathrm{Bn} \\
\mathrm{Q}_{\mathrm{mx}}=0,337 . \mathrm{A}^{0,847}
\end{gathered}
$$

$\mathrm{R}^{2}$

$\mathrm{R}^{2} \mathrm{a}$
0,98

ep

$\mathrm{CV}$

I b) Modelo da curva regional (Gumbel)

$$
\begin{array}{cc}
\left(\mathrm{Q}_{50} / \mathrm{Q}_{\mathrm{mx}}\right)_{\mathrm{R}} & \mathrm{R}^{2} \\
2,083 & 0,93
\end{array}
$$

0,98

1,17

2,97

$1,3 \mathrm{E}-5$

ep

$\% \mathrm{~F}$

0,11

Região - II

II a) Modelo de regressão múltipla da vazão média máxima
$\mathrm{Y}=\mathrm{B} 0{ }^{*} \mathrm{x} 1^{\wedge} \mathrm{B} 1{ }^{*} \mathrm{x} 2^{\wedge} \mathrm{B} 2{ }^{*} \ldots \ldots .{ }^{*} \mathrm{xn}{ }^{\wedge} \mathrm{Bn}$
$\mathrm{R}^{2}$
$\mathrm{Q}_{\mathrm{mx}}=0,122 \mathrm{~A}^{0,878}$. Dc 0,664
0,95
$\mathrm{R}^{2} \mathrm{a}$
ep
CV
$\% \mathrm{~F}$
II b) Modelo da curva regional (Gumbel)
$\left(\mathrm{Q}_{50} / \mathrm{Q}_{\mathrm{mx}}\right)_{\mathrm{R}}$
2,294
$\mathrm{R}^{2}$
0,90
0,94

1,24
4,13
9,0E-3
ep
$\% \mathrm{~F}$
0,15
0,00

Região - III

III a) Modelo de regressão múltipla da vazão média máxima

$$
\begin{array}{ccc}
\mathrm{Y}=\mathrm{B} 0{ }^{*} \mathrm{x}^{\wedge} \mathrm{B} 1{ }^{*} \mathrm{x} 2^{\wedge} \mathrm{B} 2{ }^{*} \ldots \ldots . .{ }^{*} \mathrm{xn}^{\wedge} \mathrm{Bn} & \mathrm{R}^{2} \\
\mathrm{Q}_{\mathrm{mx}} & =0,499 . \mathrm{A}{ }^{0,820} & 0,83
\end{array}
$$

$\mathrm{R}^{2} \mathrm{a}$

0,82

ep

1,60

$\mathrm{CV}$

$\% \mathrm{~F}$

III b) Modelo da curva regional (Gumbel)

$$
\left(\mathrm{Q}_{50} / \mathrm{Q}_{\mathrm{mx}}\right)_{\mathrm{R}}
$$

$\mathrm{R}^{2}$

2,188

0,86

ep

0,17

$1,9 \mathrm{E}-4$

9,51

$\% \mathrm{~F}$

0,00

podem ser considerados de excelente a bom relativamente aos parâmetros estatísticos $\mathrm{R}^{2} ; \mathrm{R}^{2} \mathrm{a} ; \mathrm{Ep} ; \mathrm{Cv}$ e $\% \mathrm{~F}$.

Quanto ao ajustamento do modelo da curva regional $\left(\mathrm{Q}_{50} / \mathrm{Q}_{\mathrm{mx}}\right)_{\mathrm{R}}$ os parâmetros de ajustamento da regressão $\left(\mathrm{R}^{2} ; \mathrm{R}^{2} \mathrm{a} ; \mathrm{Ep} ; \mathrm{Cv}\right.$ e $\left.\% \mathrm{~F}\right)$ mostram resultados que foram considerados bons.

Como ilustração da parte gráfica do programa RH3.0 a Figura 3 apresenta o ajuste da distribuição de probabilidades log-normal a dois parâmetros aos dados das vazões máximas, da estação fluviométrica (sub-bacia) Ponte do Vilela aplicando o método I. Já a Figura 4 mostra o ajuste da curva regional aos dados das vazões máximas adimensionalizadas no papel probabilístico de Gumbel, aplicando o método II na região hidrológicamente homogênea I.

A Tabela 7 apresenta o termo adimensional da curva de probabilidade regional no papel probabilístico de Gumbel $\left(\mathrm{Q}_{50} / \mathrm{Q}_{\mathrm{mx}}\right)_{\mathrm{R}}$ nas três regiões hidrológicamente homogêneas, para os períodos de retorno de $2,5,10,20,50,100$ e 500 anos, com intervalos de confiança de 95 e $99 \%$.

No sentido de uniformizar as equações dos modelos de vazão específica máxima, foi elaborado a Tabela 8 utilizando os dados das Tabelas 6 e 7. As equações dos modelos de vazões foram obtidas através do produto do intercepto do modelo de regressão múltipla da vazão média máxima (Tabela 6) pelo termo adimensional da curva de probabilidade regional (Tabela 7). A seguir, dividindo-se o produto pela área da bacia (A) obteve-se a vazão específica em $\mathrm{m}^{3} / \mathrm{s} . \mathrm{km}^{2}$.

Regionalização da curva de permanência - As regiões identificadas como hidrologicamente homogênea para a curvas de pemanência foram as mesmas para as vazões máximas, mínimas e média de longo período, conforme apresentadas na Figura 2.

A Tabela 9 apresenta as probabilidades de 50 a $95 \%$ da curva de permanência de vazões médias diárias das sub-bacias estudadas e a Figura 5 ilustra a curva de permanência das vazões diárias do rio Ajudas, na estação Fazenda Ajudas para o período de 1964 a 1992.

A Tabela 10 apresenta os modelos selecionados para as probabilidades de 50 a $95 \%$.

Nesta observa-se que os modelos selecionados para as probabilidades de $50 \%$ a $95 \%$ nas três 
regiões apresentam resultados excelentes quanto aos parâmetros estatísticos $\mathrm{R}^{2}, \mathrm{R}^{2} \mathrm{a}, \mathrm{Ep}, \mathrm{Cv}$ e \% F.

Comentários:

1. Como os valores das estações de Porto Mesquita, Ponte Vilela, Porto Pará, Porto das Andorinhas apresentavam layout dife-

Tabela 7. Valores do termo adimensional da curva regional de vazão máxima $\left(\mathrm{m}^{3} / \mathrm{s}\right)$ com os períodos de retorno e intervalos de confiança estudados nas três regiões.

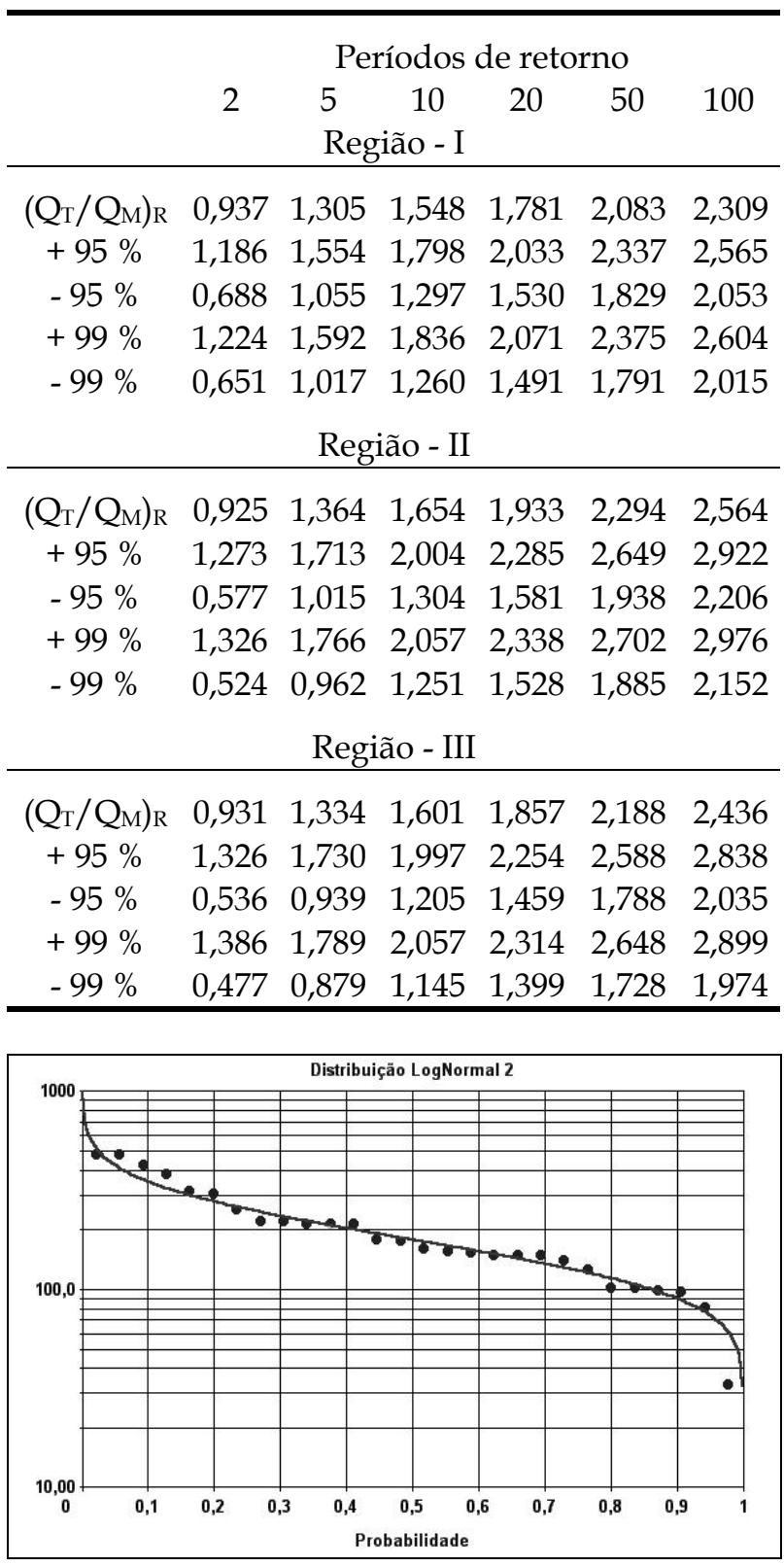

Figura 3. Ajuste da distribuição log-normal - II às vazões específicas máximas $\left(q_{50}\right)$ do rio Pará em Ponte do Vilela. rente do padrão ANEEL (série histórica cedida pela CEMIG) não foi possível estimar os valores das probabilidades da curva de permanência dos dados diários destas estações pelo RH3.0.

Tabela 8. Modelos selecionados de vazão específica máxima diária anual $\left(\mathrm{m}^{3} / \mathrm{s} . \mathrm{km}^{2}\right)$ e os períodos de retorno estudados nas três regiões.

\begin{tabular}{clc}
\hline $\begin{array}{l}\text { Período de } \\
\text { retorno }\end{array}$ & Variáveis & \multicolumn{1}{c}{$\begin{array}{c}\text { Modelos } \\
\text { selecionados }\end{array}$} \\
\hline 2 & Região - I & \\
5 & Área & $\mathrm{q}=0,316 \cdot \mathrm{A}^{--0,153}$ \\
10 & Área & $\mathrm{q}=0,440 \cdot \mathrm{A}^{-0,153}$ \\
20 & Área & $\mathrm{q}=0,522 \cdot \mathrm{A}^{--0,153}$ \\
50 & Área & $\mathrm{q}=0,600 \cdot \mathrm{A}^{-0,153}$ \\
100 & Área & $\mathrm{q}=0,702 \cdot \mathrm{A}^{-0,153}$ \\
\multicolumn{3}{c}{ Região - II } \\
\hline
\end{tabular}

\begin{tabular}{|c|c|c|}
\hline 2 & Área, Decliv. rio & $q=0,113 \cdot A^{-0,122} \cdot D^{0,664}$ \\
\hline 5 & Área, Decliv. rio & $q=0,166 \cdot A^{-0,122} \cdot D^{0,664}$ \\
\hline 10 & Área, Decliv. rio & $q=0,202 \cdot A^{-0,122} \cdot$ Dc $^{0,66}$ \\
\hline 20 & Área, Decliv. rio & $\mathrm{q}=0,236 \cdot \mathrm{A}^{-0,122} \cdot \mathrm{Dc}^{0,664}$ \\
\hline 50 & Área, Decliv. rio & $\mathrm{q}=0,280 \cdot \mathrm{A}^{-0,122} \cdot \mathrm{Dc}^{0,664}$ \\
\hline 100 & Área, Decliv. rio & $\mathrm{q}=0,313 \cdot \mathrm{A}^{-0,122} \cdot \mathrm{Dc}^{0,664}$ \\
\hline \multicolumn{3}{|c|}{ Região - III } \\
\hline 2 & Área & $q=0,456 . A^{-0,180}$ \\
\hline 5 & Área & $q=0,666 . A^{-0,180}$ \\
\hline 10 & Área & $q=0,799 . A^{-0,180}$ \\
\hline 20 & Área & $q=0,927 . A^{-0,180}$ \\
\hline 50 & Area & $q=1,092 . A^{-0,180}$ \\
\hline 100 & Área & $q=1,216 . A-0.180$ \\
\hline \multicolumn{3}{|c|}{ Papel de Probabilidade - Distr. Gumbel } \\
\hline \multicolumn{3}{|l|}{2,700} \\
\hline \multicolumn{3}{|l|}{2,400} \\
\hline \multicolumn{3}{|l|}{2,100} \\
\hline \multicolumn{3}{|l|}{1,800} \\
\hline \multicolumn{3}{|l|}{1,500} \\
\hline \multicolumn{3}{|l|}{0,900} \\
\hline \multicolumn{3}{|l|}{0,600} \\
\hline \multicolumn{3}{|l|}{0,300} \\
\hline \multirow{2}{*}{0,000} & 2 & 10 \\
\hline & Tempo de & Retorno \\
\hline
\end{tabular}

Figura 4. Ajuste da curva regional das vazões máximas adimensionalizadas $\left(Q_{10} / Q_{m x}\right)_{R}$ no papel probabilístico de Gumbel, na região I. 
Tabela 9. Probabilidades de 50 a 95\% das vazões médias diárias $\left(\mathrm{m}^{3} / \mathrm{s}\right)$ das sub-bacias estudadas.

\begin{tabular}{lrrrrrr}
\hline Nome & A & \multicolumn{5}{c}{ Probabilidades } \\
Sub-bacia & $\left(\mathrm{km}^{2}\right)$ & $50 \%$ & $65 \%$ & $75 \%$ & $85 \%$ & $95 \%$ \\
\hline U. J. Ribeiro & 259 & 2,9 & 2,2 & 1,9 & 1,6 & 1,2 \\
E. R. de Minas & 469 & 5,8 & 4,5 & 3,8 & 3,1 & 2,3 \\
Belo Vale & 2690 & 34,2 & 26,6 & 23,1 & 19,7 & 15,8 \\
Alberto Flores & 3945 & 43,3 & 34,5 & 29,1 & 24,6 & 19,6 \\
C. do Itagua & 649 & 8,4 & 6,8 & 6,0 & 5,1 & 3,4 \\
P. N. Paraopeba & 5663 & 65,6 & 52,0 & 44,5 & 37,9 & 30,4 \\
P. Taquara & 8571 & 84,5 & 64,8 & 55,2 & 46,6 & 36,0 \\
Marilândia & 533 & 10,4 & 8,1 & 6,8 & 5,6 & 4,3 \\
Pari & 1849 & 20,9 & 16,3 & 13,8 & 11,2 & 8,3 \\
Carmo do Cajuru & 2402 & 27,3 & 21,8 & 19,2 & 17,0 & 13,4 \\
Jaguaruna-Jus. & 1543 & 15,0 & 12,5 & 11,1 & 9,6 & 7,7 \\
E. A. Silveira & 1803 & 17,9 & 14,0 & 11,7 & 9,6 & 7,1 \\
Velho Taipa & 7109 & 71,3 & 57,4 & 50,0 & 42,5 & 32,9 \\
Martinho Campos & 715 & 5,4 & 3,9 & 3,1 & 2,5 & 1,5 \\
Vargem Bonita & 350 & 5,4 & 4,2 & 3,5 & 3,0 & 2,1 \\
Faz da Barra & 743 & 11,3 & 8,4 & 7,1 & 6,1 & 5,0 \\
Faz. Sambura & 738 & 13,9 & 11,3 & 9,9 & 8,6 & 7,3 \\
Faz. Ajudas & 327 & 3,1 & 2,2 & 1,9 & 1,5 & 1,2 \\
Iguatama & 4846 & 65,7 & 48,8 & 41,5 & 35,1 & 28,2 \\
Tapiraí-Jus. & 543 & 9,6 & 7,8 & 6,9 & 6,1 & 5,0 \\
M. B. Sucesso & 269 & 3,9 & 3,1 & 2,7 & 2,3 & 1,9 \\
Calciolândia & 276 & 1,4 & 1,0 & 0,8 & 0,6 & 0,3 \\
P. Chumbo & 9255 & 116,2 & 83,7 & 69,3 & 58,8 & 47,0 \\
Taquaral & 623 & 4,2 & 2,7 & 2,1 & 1,6 & 1,0 \\
Barra Funchal & 881 & 8,4 & 6,0 & 4,9 & 4,0 & 2,8 \\
F. B. Jardim & 1708 & 14,6 & 10,2 & 8,4 & 6,9 & 5,4 \\
Abaeté & 466 & 4,8 & 2,5 & 1,7 & 1,2 & 0,7 \\
Faz. São Félix & 905 & 7,2 & 4,8 & 4,0 & 3,0 & 2,2 \\
\hline & & & & &
\end{tabular}

2. As sub-bacias que apresentaram menores disponibilidades hídricas na região, foram as mesmas identificadas na regionalização da vazão mínima de sete dias de duração e período de retorno de 10 anos, quais sejam: Calciolândia, Abaeté e Taquaral.

Tendo em vista que as vazões com intervalo diário e $95 \%$ de permanência são frequentemente utilizadas em sistemas de captação a fio d'água, como também em estudos de outorga de uso de água superficial, foi realizada uma análise comparativa desta vazão com a vazão mínima de sete dias de duração e período de retorno de 10 anos (Tabela 11).

Os valores das vazões mínimas de sete dias de duração e período de retorno de 10 anos são resultantes da aplicação da distribuição de proba-
Tabela 10. Modelos de regressão das vazões $\left(\mathrm{m}^{3} / \mathrm{s}\right)$ para as probabilidades de 50 a $95 \%$ nas três regiões.

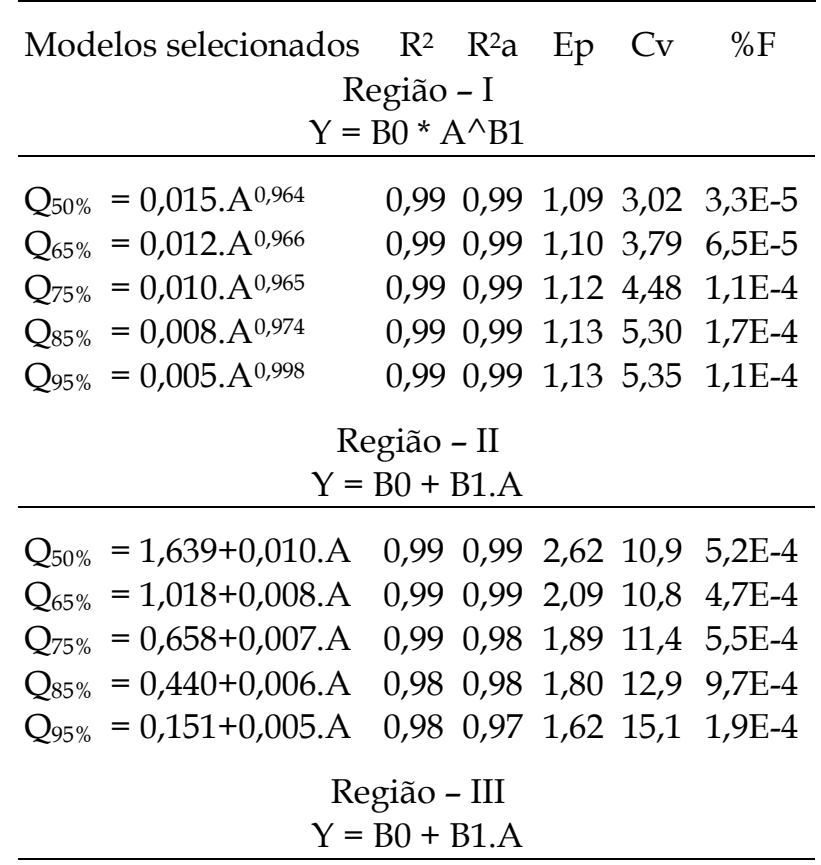

$\mathrm{Q}_{50 \%}=-0,727+0,013$.A $\quad 0,99 \quad 0,99 \quad 3,44 \quad 17,9$ 3,1E-11

$\mathrm{Q}_{65 \%}=-0,431+0,009$.A $\quad 0,98 \quad 0,98 \quad 3,06 \quad 21,8 \quad 3,5 \mathrm{E}-10$

$\mathrm{Q}_{75 \%}=-0,267+0,008$.A $\quad 0,98 \quad 0,98 \quad 2,83 \quad 23,9$ 1,2E-09

$\mathrm{Q}_{85 \%}=-0,294+0,006 . \mathrm{A} \quad 0,98 \quad 0,97 \quad 2,54 \quad 25,6 \quad 2,4 \mathrm{E}-09$

$\mathrm{Q}_{95 \%}=-0,317+0,005$.A $0,97 \quad 0,97 \quad 2,19$ 27,9 5,9E-09

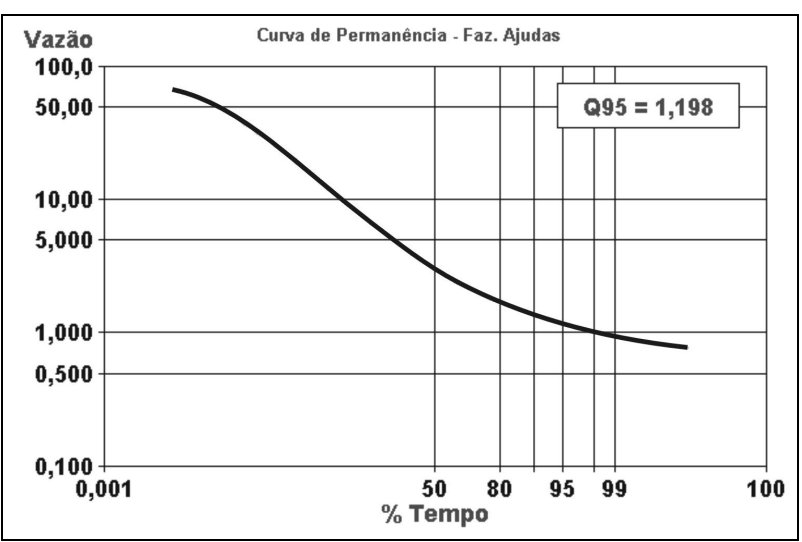

Figura 5. Curva de permanência de vazões diárias do rio Ajudas em Fazenda Ajudas, para o período de 1964 a 1992.

bilidades log-normal-III aos dados das sub-bacias estudadas (método I do RH3.0).

A Figura 6 ilustra o comportamento das vazões estudadas em função das áreas das subbacias, com também a equação das retas de regressão para as referidas vazões. Conforme pode-se observar os valores das vazões estão próximos para 


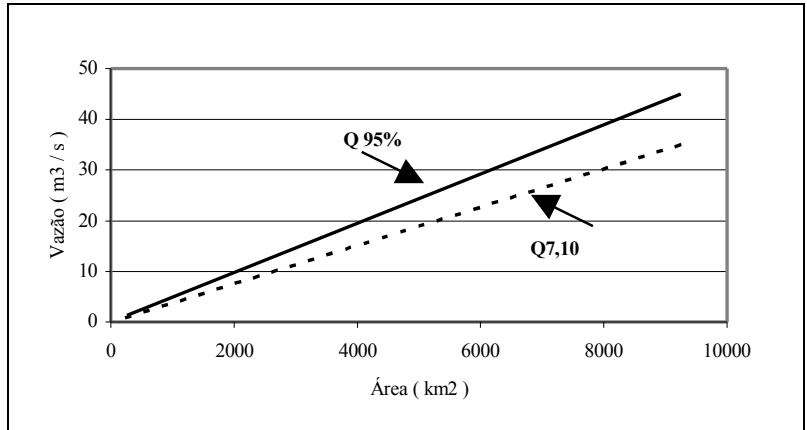

Figura 6. Vazão mínima de sete dias de duração e período de retorno de 10 anos $\left(Q_{7,10}\right)$ versus vazão obtida da curva de permanência para $95 \%$ de probabilidade $\left(\mathbf{Q}_{95 \%}\right)$.

pequenas bacias de drenagem (em torno de $300 \mathrm{~km}^{2}$ ) e a vazão com $95 \%$ de permanência $\left(Q_{95 \%}\right)$ apresenta valores superiores a vazão mínima com sete dias de duração e período de retorno de 10 anos $\left(Q_{7,10}\right)$, com o aumento das áreas das bacias.

Mapeamento de vazões específicas - Foram mapeadas as vazões específicas mais empregadas em projetos de aproveitamento hídrico, quais sejam:

a. vazão máxima com período de retorno de 50 anos - controle de enchentes em áreas agrícolas, por meio da técnica de dragagem de curso d'água, pequenas barragens de terra;

b. vazão mínima de sete dias de duração e período de retorno de 10 anos - estudos de qualidade d'água e estudos para a concessão do uso da água para uma dada finalidade;

c. vazão média de longo período - máxima vazão, possível de ser regularizada em uma bacia hidrográfica;

d. vazão com intervalo diário e 95\% de permanência - utilizadas em sistemas de captação a fio d'água e estudos de outorga de uso de água superficial.

Para trabalhar no intervalo das áreas de contribuição das sub-bacias estudadas, ou seja, de $259 \mathrm{~km}^{2}$ a $13.300 \mathrm{~km}^{2}$ e obter uma densidade de pontos satisfatória, subdividiu-se a área estudada em pequenas sub-bacias com áreas em torno de $500 \mathrm{~km}^{2}$, totalizando 26 sub-bacias.

Os mapas obtidos são válidos para vazões específicas da ordem de $500 \mathrm{~km}^{2}$. Para bacias com
Tabela 11. Vazão mínima de sete dias de duração e período de retorno de 10 anos $\left(Q_{7,10}\right)$ versus vazão obtida da curva de permanência para $95 \%$ de probabilidade $\left(\mathrm{Q}_{95 \%}\right)$.

\begin{tabular}{|c|c|c|c|c|}
\hline $\begin{array}{l}\text { Nome } \\
\text { Sub-bacia }\end{array}$ & $\begin{array}{l}\text { Área } \\
\left(\mathrm{km}^{2}\right)\end{array}$ & $\begin{array}{c}Q_{7,10} \\
\left(\mathrm{~m}^{3} / \mathrm{s}\right)\end{array}$ & $\begin{array}{c}\mathrm{Q}_{95 \%} \\
\left(\mathrm{~m}^{3} / \mathrm{s}\right)\end{array}$ & $\begin{array}{c}\text { Desv.\% } \\
1-\left(Q_{7,10} / Q_{95}\right)\end{array}$ \\
\hline Usina J. Ribeiro & 259 & 1,01 & 1,21 & 16,53 \\
\hline E. Rios de Minas & 469 & 1,53 & 2,28 & 32,89 \\
\hline Belo Vale & 2.690 & 12,21 & 15,84 & 22,92 \\
\hline Alberto Flores & 3.945 & 14,43 & 19,62 & 26,45 \\
\hline C. do Itaguá & 649 & 2,16 & 3,44 & 37,21 \\
\hline P. N. Paraopeba & 5.663 & 16,98 & 30,44 & 44,22 \\
\hline Ponte Taquara & 8.571 & 26,94 & 36,03 & 25,23 \\
\hline Marilândia & 533 & 2,49 & 4,26 & 41,55 \\
\hline Pari & 1.849 & 5,54 & 8,27 & 33,01 \\
\hline C. do Cajuru & 2.402 & 13,35 & 13,36 & 0,07 \\
\hline Jaguaruna-Jus. & 1.543 & 4,96 & 7,69 & 35,50 \\
\hline E. A. Silveira & 1.803 & 4,39 & 7,11 & 38,26 \\
\hline Velho Taipa & 7.109 & 28,87 & 32,95 & 12,38 \\
\hline M. Campos & 715 & 1,05 & 1,51 & 30,46 \\
\hline Vargem Bonita & 350 & 2 & 2,09 & 4,31 \\
\hline Faz. da Barra & 743 & 3,88 & 4,99 & 22,24 \\
\hline Faz. Sambura & 738 & 5,96 & 7,29 & 18,24 \\
\hline Faz. Ajudas & 327 & 0,95 & 1,2 & 20,83 \\
\hline Iguatama & 4.846 & 24,68 & 28,17 & 12,39 \\
\hline Tapiraí-Jus & 543 & 4,04 & 5,03 & 19,68 \\
\hline M. B. Sucesso & 269 & 1,47 & 1,92 & 23,44 \\
\hline Calciolândia & 276 & 0,23 & 0,35 & 34,29 \\
\hline P. Chumbo & 9.255 & 37,62 & 46,99 & 19,94 \\
\hline Taquaral & 623 & 0,58 & 1,05 & 44,76 \\
\hline Barra Funchal & 881 & 1,27 & 2,82 & 54,96 \\
\hline F. B. Jardim & 1.708 & 3,99 & 5,45 & 26,79 \\
\hline Abaeté & 466 & 0,27 & 0,68 & 60,29 \\
\hline Faz. São Félix & 905 & 1,42 & 2,2 & 35,45 \\
\hline
\end{tabular}

áreas superiores a estas, a tendência é obter-se vazões específicas menores e, em caso contrário, maiores.

As Figuras 7, 8, 9 e 10 configuram os mapas de vazões específicas médias de longo período, mínimas de sete dias de duração e período de retorno de 10 anos, máximas diárias anuais para período de retorno de 50 anos e vazão obtida da curva de permanência para $95 \%$ de probabilidades, respectivamente.

Em termos quantitativos, as classes de vazões específicas médias de longo período, mínimas de sete dias de duração e período de retorno de 10 anos, máximas diárias anuais para período de retorno de 50 anos e vazão obtida da curva de permanência para $95 \%$ de probabilidades estão distribuídas conforme as Tabelas 12, 13, 14 e 15, 


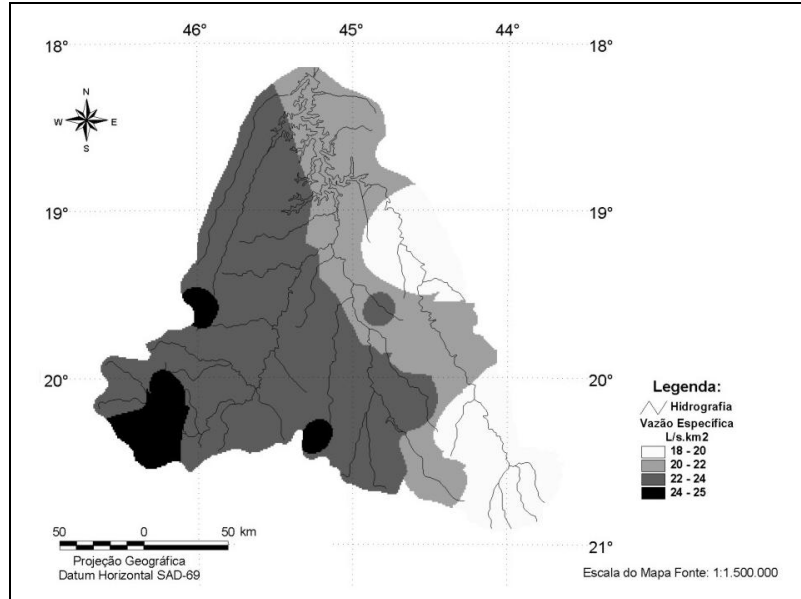

Figura 7. Vazões específicas médias de longo período.

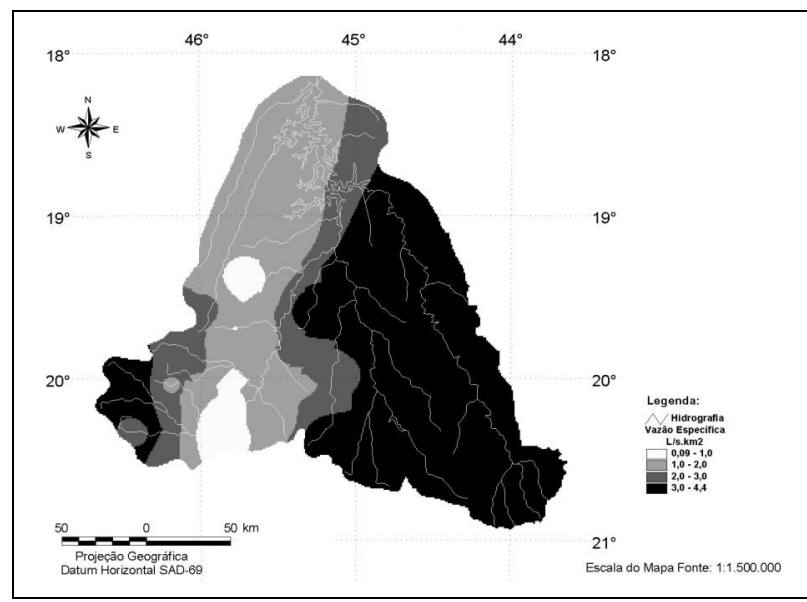

Figura 8. Vazões específicas mínimas de sete dias de duração e período de retorno de 10 anos.

respectivamente. Nestes, observa-se a maior freqüência de valores da vazão média de longo período na classe 22 a $24 \mathrm{~L} / \mathrm{s} . \mathrm{km}^{2}$, com $40,6 \%$ do total, os valores da vazão mínima na classe 3,0 a $4,4 \mathrm{~L} / \mathrm{s} . \mathrm{km}^{2}$ com $50,4 \%$, os valores da vazão máxima na classe 300 a 400 L/s.km², com 76,3\% e os valores da vazão obtida da curva de permanência para $95 \%$ de probabilidades na classe 4,5 a 5,0 L/s. km² , com 53,1\%.

Quanto à vazão específica média de longo período (Figura 7), observa-se que os maiores valores ocorreram nas áreas a sudoeste e numa pequena área a oeste e norte da bacia. Já os menores valores ocorreram em, praticamente, toda a região sudeste e leste (Região I), estendendo-se ao longo de toda a bacia do rio Paraobepa.

Conforme a Figura 8, os maiores valores da vazão específica mínima, para período de retorno de 10 anos, predominaram nas áreas a leste da ba-

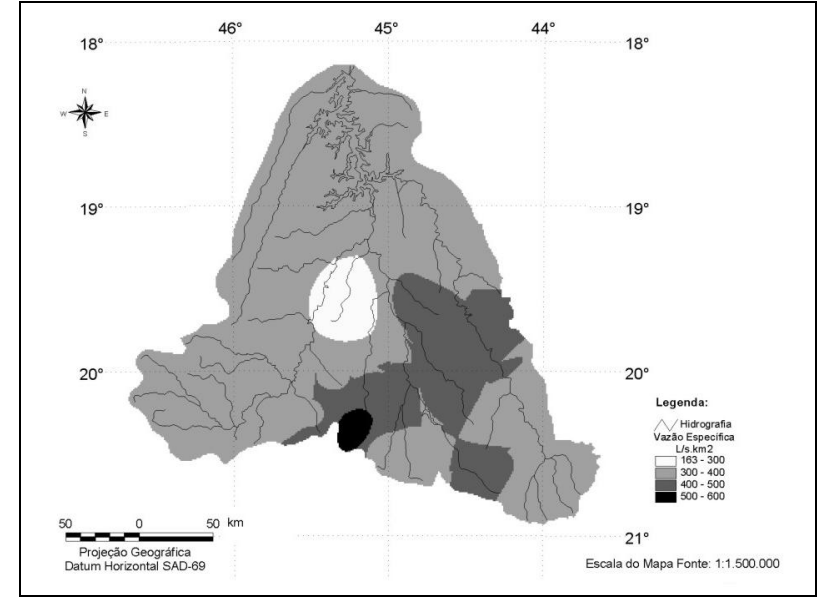

Figura 9. Vazões específicas máximas diárias anuais para período de retorno de 50 anos.

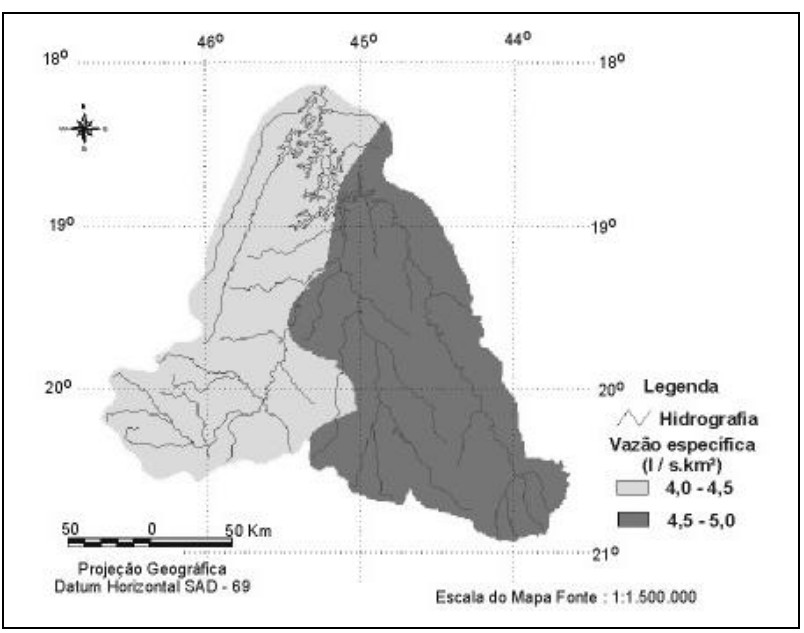

Figura 10. Vazões específicas obtidas da curva de permanência para a probabilidade de $95 \%$.

cia (Regiões I e II) estendendo-se na direção centro e leste, e numa pequena área situada ao extremo sudoeste da bacia. Os menores valores predominaram nas áreas a sudoeste da bacia.

Na Figura 9, observa-se que os maiores valores da vazão específica máxima para período de retorno de 50 anos, estão localizados em uma pequena área ao sul, os menores valores situados no centro da bacia e predominando na bacia os valores entre 300 e $400 \mathrm{~L} / \mathrm{s} . \mathrm{Km}^{2}$.

Para a vazão obtida da curva de permanência para 95\% de probabilidades (Figura 10), observa-se uma divisão da bacia em duas áreas, uma a leste (Regiões I e II) e outra a oeste (Região III). Os menores valores predominaram na área a oeste da bacia, ao longo de todo o rio São Francisco até a barragem de Três Marias. 
Tabela 12. Classes de vazões específicas médias de longo período.

\begin{tabular}{crcc}
\hline $\begin{array}{c}\text { Classes } \\
\left(\mathrm{L} / \mathrm{s} . \mathrm{km}^{2}\right)\end{array}$ & $\begin{array}{r}\text { Área } \\
\left(\mathrm{km}^{2}\right)\end{array}$ & $\begin{array}{c}\text { Percentual } \\
(\%)\end{array}$ & $\begin{array}{c}\text { Acumulado } \\
(\%)\end{array}$ \\
\hline $18-20$ & 6.652 & 13,2 & 13,2 \\
$20-22$ & 10.734 & 21,3 & 34,5 \\
$22-24$ & 20.460 & 40,6 & 75,1 \\
$24-25$ & 12.548 & 24,9 & 100,0 \\
Total & 50.394 & - & - \\
\hline
\end{tabular}

Tabela 13. Classes de vazões específicas mínimas para período de retorno de $\mathbf{1 0}$ anos.

\begin{tabular}{crcc}
\hline $\begin{array}{c}\text { Classes } \\
\left(\mathrm{L} / \mathrm{s} . \mathrm{km}^{2}\right)\end{array}$ & $\begin{array}{r}\text { Área } \\
\left(\mathrm{km}^{2}\right)\end{array}$ & $\begin{array}{r}\text { Percentual } \\
(\%)\end{array}$ & $\begin{array}{c}\text { Acumulado } \\
(\%)\end{array}$ \\
\hline $0,09-1,0$ & 2.090 & 4,1 & 4,1 \\
$1,0-2,0$ & 14.816 & 29,4 & 33,5 \\
$2,0-3,0$ & 8.103 & 16,1 & 49,6 \\
$3,0-4,4$ & 25.385 & 50,4 & 100,0 \\
Total & 50.394 & - & - \\
\hline
\end{tabular}

\section{REGIONALIZAÇÃO HIDROLÓGICA II/II}

As estações hidrométricas, o período-base e os valores das variáveis hidrológicas foram os mesmos utilizados na Regionalização Hidrológica I/II.

Considerando que os modelos resultantes da aplicação da regressão simples entre a precipitação média anual (mm/ano) com: a vazão média de longo período $\left(\mathrm{m}^{3} / \mathrm{s}\right)$, o deflúvio médio anual (mm/ano) e a vazão específica média de longo período $\left(\mathrm{L} / \mathrm{s} . \mathrm{km}^{2}\right)$ apresentaram ajustamentos ruins (o maior coeficiente de determinação obtido foi de 0,001 para a segunda e terceira tentativa), decidiu-se por uma quarta tentativa. Esta consistiu em incluir na regressão, o coeficiente de escoamento anual (relação entre o volume escoado e precipitado, nas sub-bacias estudadas).

Assim sendo, realizou-se regressão múltipla entre a vazão específica média de longo período $\left(\mathrm{q}_{\mathrm{mlp}}\right)$ com a precipitação pluvial média anual (Pma) e o coeficiente de escoamento anual (C). Os modelos que apresentaram melhores ajustamentos foram o logaritmo e o exponencial, ambos com $\mathrm{R}^{2}=0,98$. Por apresentar menor erro padrão fatorial na regressão $\left(\sigma_{\mathrm{F}}=0,03\right)$, foi selecionado o modelo exponencial para representar a vazão específica.
Tabela 14. Classes de vazões específicas máximas para período de retorno de 50 anos.

\begin{tabular}{crcc}
\hline $\begin{array}{c}\text { Classes } \\
\left(\mathrm{L} / \mathrm{s} . \mathrm{km}^{2}\right)\end{array}$ & $\begin{array}{r}\text { Área } \\
\left(\mathrm{km}^{2}\right)\end{array}$ & $\begin{array}{r}\text { Percentual } \\
(\%)\end{array}$ & $\begin{array}{c}\text { Acumulado } \\
(\%)\end{array}$ \\
\hline $163-300$ & 2.110 & 4,2 & 4,2 \\
$300-400$ & 37.943 & 76,3 & 80,5 \\
$400-500$ & 9.831 & 19,5 & 99,0 \\
$500-600$ & 510 & 1,0 & 100,0 \\
Total & 50.394 & - & - \\
\hline
\end{tabular}

Tabela 15. Vazões específicas obtidas da curva de permanência para a probabilidadede $95 \%$.

\begin{tabular}{cccc}
\hline $\begin{array}{c}\text { Classes } \\
\left(\mathrm{L} / \mathrm{s} . \mathrm{km}^{2}\right)\end{array}$ & $\begin{array}{c}\text { Área } \\
\left(\mathrm{km}^{2}\right)\end{array}$ & $\begin{array}{c}\text { Percentual } \\
(\%)\end{array}$ & $\begin{array}{c}\text { Acumulado } \\
(\%)\end{array}$ \\
\hline $4,0-4,5$ & 23.645 & 46,9 & 46,9 \\
$4,5-5,0$ & 26.749 & 53,1 & 100,0 \\
Total & 50.394 & - & - \\
\hline
\end{tabular}

A Equação (21) corresponde ao modelo selecionado da vazão específica média de longo período $\left(\mathrm{L} / \mathrm{s} . \mathrm{km}^{2}\right)$ para toda a área estudada. Para se obter a vazão média de longo período $\left(\mathrm{Q}_{\mathrm{mlp}}\right)$ em litros por segundo, basta multiplicar o resultado desta equação pela área da bacia $\mathrm{em}^{\mathrm{km}^{2}}$ (Equação 22).

$$
\begin{gathered}
\mathrm{q}_{\mathrm{mlp}}=2,38 \cdot \mathrm{e}^{[((0,0008 \cdot \mathrm{Pma})+(2,21 \cdot \mathrm{C})]} \\
\mathrm{Q}_{\mathrm{mlp}}=\left\{2,38 \cdot \mathrm{e}^{[(0,0008 \cdot \mathrm{Pma})+(2,21 \cdot \mathrm{C})]}\right\} \cdot A
\end{gathered}
$$

Objetivando facilitar a coleta das variáveis hidrológicas para se aplicar no modelo selecionado, realizou-se a espacialização da precipitação média anual e do coeficiente de escoamento médio anual na bacia, conforme pode ser observado nas Figuras 11 e 12, respectivamente. Estas figuras foram geradas através de técnicas de sistemas de informações geográficas, utilizando os programas Arc/Info 7.1.2 e ArcView 3.0a.

Para avaliar a disponibilidade hídrica em uma dada seção de um curso d'água, situada dentro da área abrangida pelo presente trabalho, é necessário localizar a sua bacia de drenagem na Figura 11 e determinar a precipitação média anual correpondente. De maneira análoga determina-se o coeficiente de escoamento anual na Figura 12 e, a seguir, substituindo-se os valores obtidos na Equa- 


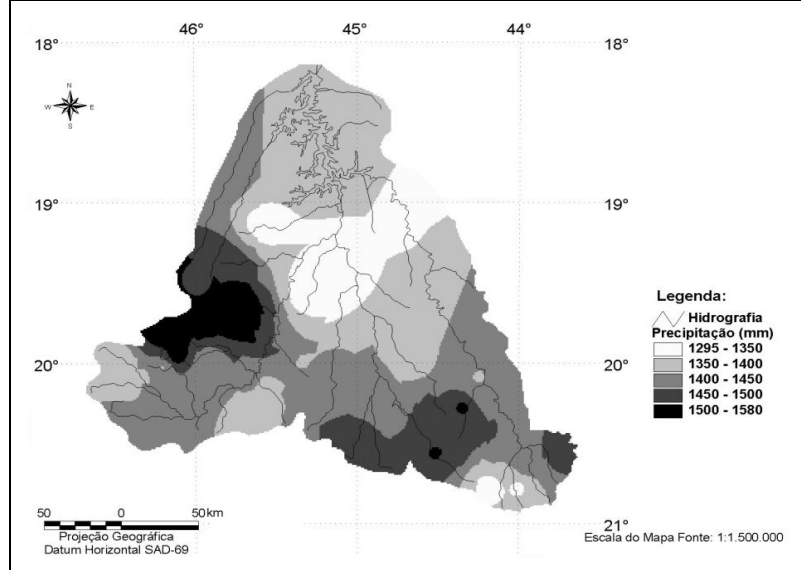

Figura 11. Precipitação média pluvial anual.

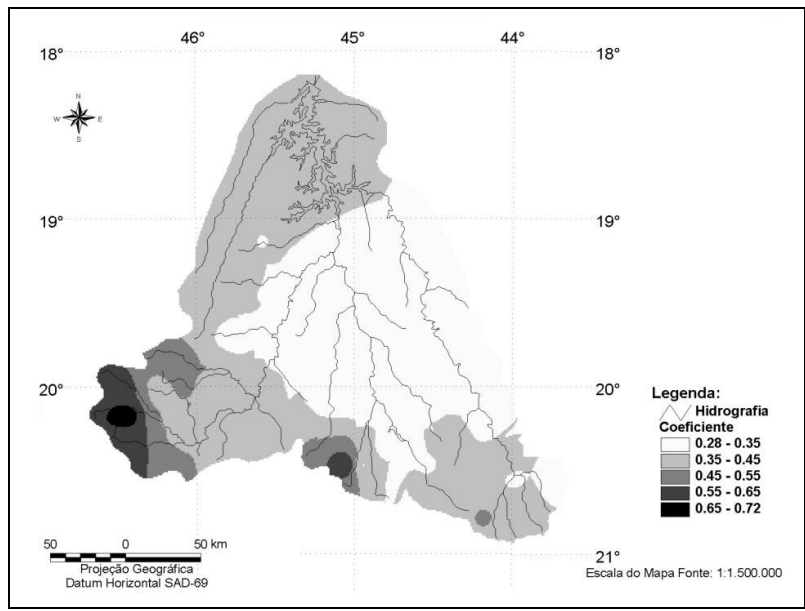

Figura 12. Coeficiente de escoamento médio anual.

ção (21) obtém-se a estimativa da vazão específica média de longo período.

Procurando facilitar o emprego da equação de regressão no processo de predição da vazão média de longo período, realizou-se nova regressão entre a vazão específica $\left(q_{\mathrm{mlp}}\right)$ e a precipitação efetiva média anual (Pef). Esta variável foi obtida através do produto da precipitação pluvial pelo coeficiente de escoamento anual (Pef = Pma . C). O modelo selecionado foi o linear simples com $R^{2}=0,999$, conforme Equação (23). As correlações encontradas utilizando estes valores podem ser observadas na Figura 13.

As sub-bacias estudadas com as variáveis e parâmetros utilizados na aplicação da metodologia se encontram na Tabela 16.

$$
\mathrm{q}_{\mathrm{mlp}}=[0,0317 \text { (Pef.) }+0,0271]
$$

A seguir, procedeu-se a espacialização da precipitação efetiva média anual na área estudada,

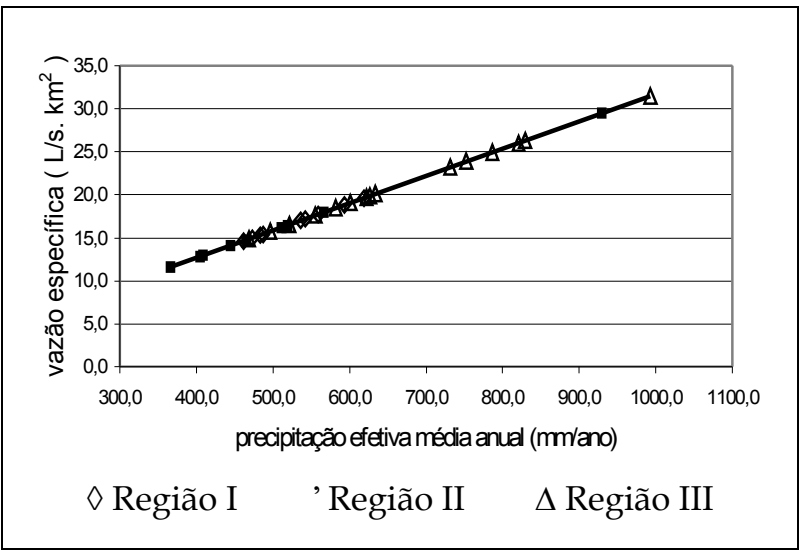

Figura 13. Correlação precipitação efetiva x vazão média de longo período para a região estudada.

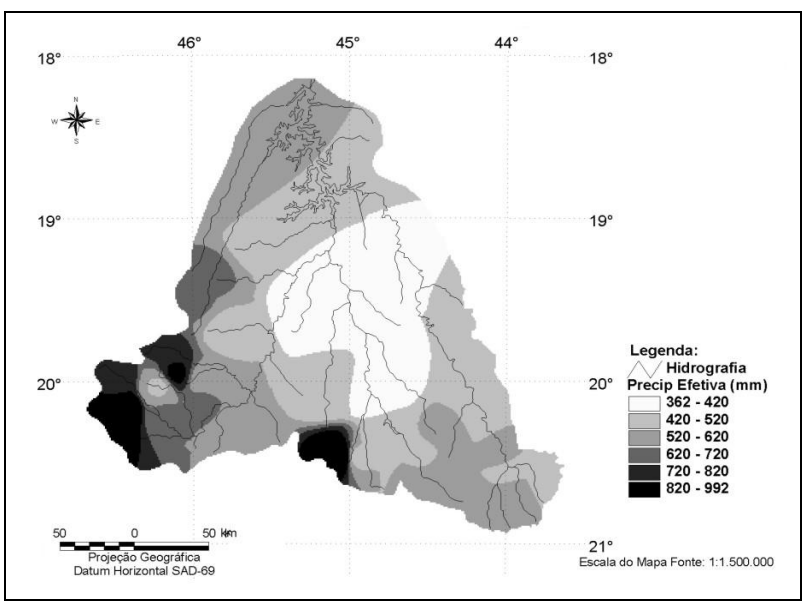

Figura 14. Precipitação efetiva média pluvial total anual.

utilizando os mesmos procedimentos adotados anteriormente, conforme pode ser visto na Figura 14.

No sentido de se obter as estimativas das vazões mais utilizadas em projetos de aproveitamento hídrico, a partir da vazão média de longo período, partiu-se para a tentativa de correlação desta vazão com:

a. vazões mínimas diárias de sete dias de duração e período de retorno de 10 anos;

b. vazões máximas diárias anuais com período de retorno de 50 anos e;

c. vazões diárias com permanência de $95 \%$.

A Tabela 17 apresenta os valores das vazões estudadas, nas trinta e três sub-bacias da região, obtidos por meio da aplicação dos modelos selecionados nas Tabelas 2, 5, 8 e 10, respectivamente, vazões médias, mínimas, máximas e vazões com permanência de $95 \%$. 
Tabela 16. Distribuição das variáveis e dos coeficientes de escoamento médio anual para as sub-bacias estudadas.

\begin{tabular}{|c|c|c|c|c|c|c|c|}
\hline Sub-bacia & $\begin{array}{c}\mathrm{A} \\
\left(\mathrm{km}^{2}\right) \\
\end{array}$ & $\begin{array}{c}\text { Pma } \\
\text { (mm/ano) }\end{array}$ & $\begin{array}{c}\text { Qmlp } \\
\left(\mathrm{m}^{3} / \mathrm{s}\right)\end{array}$ & $\begin{array}{c}\text { qmlp } \\
\left(\mathrm{L} / \mathrm{s} . \mathrm{km}^{2}\right) \\
\end{array}$ & $\begin{array}{c}\mathrm{D} \\
(\mathrm{mm} / \mathrm{ano}) \\
\end{array}$ & $\mathrm{C}$ & $\begin{array}{c}\text { Pef. } \\
\text { (mm/ano) }\end{array}$ \\
\hline U. João Ribeiro & 259 & 1341 & 4,4 & 17,0 & 535,7 & 0,40 & 535,7 \\
\hline E. R. de Minas & 469 & 1336 & 9,2 & 19,6 & 618,6 & 0,46 & 618,6 \\
\hline Congonhas & 613 & 1478 & 9,2 & 15,0 & 473,3 & 0,32 & 473,3 \\
\hline Belo Vale & 2690 & 1409 & 50,6 & 18,8 & 593,2 & 0,42 & 593,2 \\
\hline Alberto Flores & 3945 & 1442 & 60,4 & 15,3 & 482,8 & 0,33 & 482,8 \\
\hline C. do Itagua & 649 & 1508 & 11,5 & 17,7 & 558,8 & 0,37 & 558,8 \\
\hline P. Paraopeba & 5663 & 1449 & 97,4 & 17,2 & 542,4 & 0,37 & 542,4 \\
\hline P. do Taquara & 8571 & 1417 & 125,3 & 14,6 & 461,0 & 0,33 & 461,0 \\
\hline Porto Mesquita & 10300 & 1396 & 159 & 15,4 & 486,8 & 0,35 & 486,8 \\
\hline Marilândia & 533 & 1458 & 15,7 & 29,5 & 928,9 & 0,64 & 928,9 \\
\hline Pari & 1849 & 1461 & 30,4 & 16,4 & 518,5 & 0,35 & 518,5 \\
\hline Ponte do Vilela & 1620 & 1504 & 29,1 & 18,0 & 566,5 & 0,38 & 566,5 \\
\hline C. do Cajuru & 2402 & 1490 & 38,9 & 16,2 & 510,7 & 0,34 & 510,7 \\
\hline Jaguaruna-Jus. & 1543 & 1374 & 20,0 & 13,0 & 408,8 & 0,30 & 408,8 \\
\hline E. A. da Silveira & 1803 & 1415 & 25,4 & 14,1 & 444,3 & 0,31 & 444,3 \\
\hline Velho da Taipa & 7109 & 1433 & 104,8 & 14,7 & 464,9 & 0,32 & 464,9 \\
\hline Porto Pará & 12300 & 1407 & 157,9 & 12,8 & 404,8 & 0,29 & 404,8 \\
\hline M. Campos & 715 & 1296 & 8,3 & 11,6 & 366,1 & 0,28 & 366,1 \\
\hline Vargem Bonita & 350 & 1426 & 9,2 & 26,3 & 828,9 & 0,58 & 828,9 \\
\hline F. da Barra & 743 & 1377 & 23,4 & 31,5 & 993,2 & 0,72 & 993,2 \\
\hline F. Sambura & 738 & 1376 & 18,4 & 24,9 & 786,3 & 0,57 & 786,3 \\
\hline F. Ajudas & 327 & 1399 & 5,4 & 16,5 & 520,8 & 0,37 & 520,8 \\
\hline Iguatama & 4846 & 1410 & 115,6 & 23,9 & 752,3 & 0,53 & 752,3 \\
\hline Tapiraí-Jusante & 543 & 1577 & 12,6 & 23,2 & 731,8 & 0,46 & 731,8 \\
\hline M. B. Sucesso & 269 & 1533 & 7,0 & 26,0 & 820,6 & 0,54 & 820,6 \\
\hline Calciolândia & 276 & 1326 & 4,1 & 14,9 & 468,5 & 0,35 & 468,5 \\
\hline P. do Chumbo & 9255 & 1421 & 182,6 & 19,7 & 622,2 & 0,44 & 622,2 \\
\hline Taquaral & 623 & 1564 & 9,8 & 15,7 & 496,1 & 0,32 & 496,1 \\
\hline P. Andorinhas & 13087 & 1416 & 249,5 & 19,1 & 601,2 & 0,42 & 601,2 \\
\hline Barra Funchal & 881 & 1490 & 17,5 & 19,9 & 626,4 & 0,42 & 626,4 \\
\hline F. Bom Jardim & 1708 & 1496 & 34,3 & 20,1 & 633,3 & 0,42 & 633,3 \\
\hline Abaeté & 466 & 1376 & 8,2 & 17,6 & 554,9 & 0,40 & 554,9 \\
\hline Faz. São Félix & 905 & 1417 & 16,7 & 18,5 & 581,9 & 0,41 & 581,9 \\
\hline
\end{tabular}

Notação: A = Área da bacia; Qmlp = vazão média de longo período; qmlp = vazão específica média de longo período; $\mathrm{D}=$ deflúvio superficial (Qmlp x 31.536/A); C = coeficiente de escoamento anual (D/Pma); Pma = precipitação média anual sobre "A"; Pef. = precipitação efetiva média anual (Pma.C).

As Figuras 15, 16 e 17 mostram as correlações e as equações dos modelos selecionados (polinomial) para as referidas vazões, e os respectivos coeficientes de correlação.

Portanto, através deste procedimento é possível avaliar as disponibilidades e as potencialidades hídricas em regiões desprovidas de registros fluviométricos, a partir da precipitação média anual espacializada na bacia hidrográfica.

Exemplo de aplicação - Para exemplificar o emprego da metodologia foi escolhida uma sub-bacia

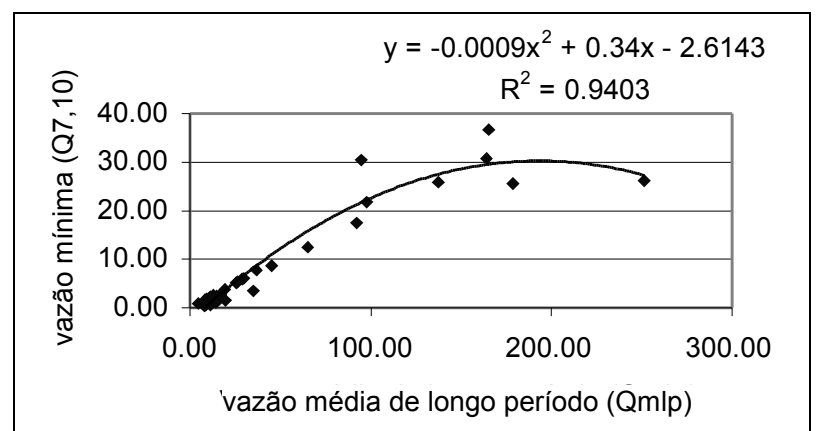

Figura 15. Correlação vazão média $\left(Q_{\mathrm{mlp}}\right)$ x vazão mínima $\left(Q_{7,10}\right)$. 


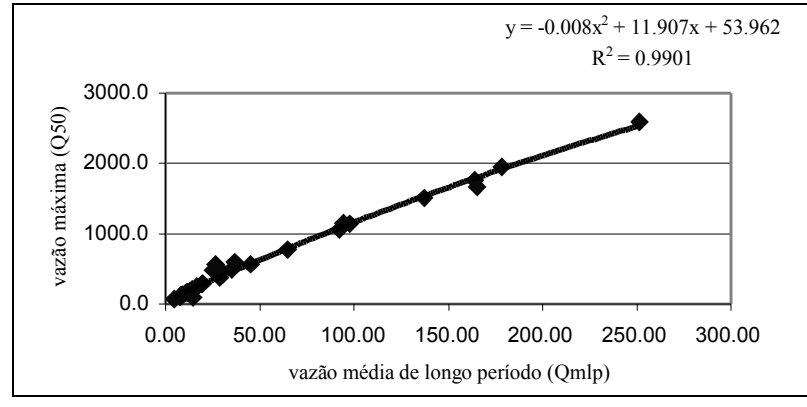

Figura 16. Correlação vazão média $\left(Q_{\mathrm{mlp}}\right)$ x vazão máxima $\left(Q_{50}\right)$.

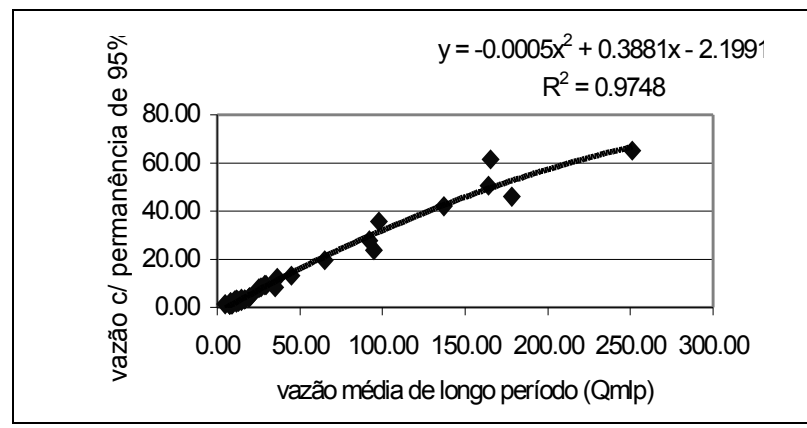

Figura 17. Correlação vazão média $\left(Q_{\mathrm{mlp}}\right)$ x vazão com permanência $95 \%\left(Q_{95 \%}\right)$.

no rio Manso, afluente do rio Paraopeba, em Conceição do Itaguá (latitude $=20^{\circ} 09^{\prime} 00^{\prime \prime}$, longitu$\left.\mathrm{de}=44^{\circ} 15^{\prime} 00^{\prime \prime}\right)$, com $649 \mathrm{~km}^{2}$ de área de drenagem, cuja localização é vista na Figura 18.

Inicialmente, a partir do mapa de precipitação efetiva média pluvial anual, determina-se a vazão média de longo período e a partir desta calculam-se as demais vazões, ou seja:

a. Cálculo da vazão média de longo período: por meio da Figura 19 determina-se a precipitação efetiva média pluvial total anual sobre a bacia obtendo-se Pef $=550 \mathrm{~mm}$. Substituindo-se este valor na Equação (23), e multiplicando pela área da bacia, determina-se Qmlp $=11,33 \mathrm{~m}^{3} / \mathrm{s}$.

b. Vazão mínima de sete dias de duração e período de retorno de 10 anos: substituindo-se Qmlp na equação polinomial da Figura 15, determina-se $\mathrm{Q}_{7,10}=1,12 \mathrm{~m}^{3} / \mathrm{s}$.

c. Vazão máxima diária anual com período de retorno de 50 anos: substituindo-se Qmlp na equação polinomial da Figura 16, determina-se $\mathrm{Q}_{50}=187,84 \mathrm{~m}^{3} / \mathrm{s}$.

d. Vazão diária com permanência de 95\%: substituindo-se Qmlp na equação polinomial da Figura 17, determina-se $Q_{95 \%}=2,13 \mathrm{~m}^{3} / \mathrm{s}$.
Tabela 17. Valores das vazões estudadas $\left(\mathrm{m}^{3} / \mathrm{s}\right)$ nas trinta e três sub-bacias da região.

\begin{tabular}{lrrrrr}
\hline Sub-bacias & Área & Qmlp & $Q_{\max 50}$ & $Q_{95 \%}$ & $Q_{7,10}$ \\
& $\left(\mathrm{~km}^{2}\right)$ & & & & \\
\hline U.João Ribeiro & 259 & 4,69 & 77,7 & 1,28 & 0,98 \\
E. Rios Minas & 469 & 8,32 & 128,5 & 2,32 & 1,71 \\
Congonhas & 613 & 10,77 & 161,2 & 3,03 & 2,19 \\
Belo Vale & 2690 & 44,89 & 564,1 & 13,24 & 8,74 \\
Alberto Flores & 3945 & 64,95 & 780,2 & 19,40 & 12,50 \\
C. do Itagua & 649 & 11,38 & 169,2 & 3,20 & 2,31 \\
P. N. Paraopeba & 5663 & 92,07 & 1059,7 & 27,83 & 17,53 \\
P. do Taquara & 8571 & 137,34 & 1505,3 & 42,09 & 25,82 \\
Porto Mesquita & 10300 & 163,99 & 1758,8 & 50,56 & 30,66 \\
Marilândia & 533 & 12,33 & 168,3 & 2,82 & 1,89 \\
Pari & 1849 & 29,44 & 484,1 & 9,40 & 6,11 \\
Ponte do Vilela & 1620 & 26,46 & 564,2 & 8,25 & 5,39 \\
C. do Cajuru & 2402 & 36,63 & 597,8 & 12,16 & 7,83 \\
Jaguaruna-Jus. & 1543 & 25,46 & 478,9 & 7,87 & 5,15 \\
E. A. Silveira & 1803 & 28,84 & 381,5 & 9,17 & 5,97 \\
Velho da Taipa & 7109 & 97,82 & 1138,7 & 35,70 & 21,82 \\
Porto Pará & 12300 & 165,30 & 1671,8 & 61,65 & 36,63 \\
M. Campos & 715 & 14,69 & 95,7 & 3,73 & 2,49 \\
Vargem Bonita & 350 & 9,19 & 133,2 & 1,43 & 1,80 \\
Faz. da Barra & 743 & 16,66 & 246,9 & 3,40 & 2,79 \\
Faz. Sambura & 738 & 16,56 & 245,5 & 3,37 & 2,58 \\
Faz .Ajudas & 327 & 8,75 & 125,9 & 1,32 & 0,61 \\
Iguatama & 4846 & 94,61 & 1148,8 & 23,91 & 30,49 \\
Tapiraí-Jusante & 543 & 12,86 & 190,9 & 2,40 & 2,62 \\
M. B. Sucesso & 269 & 7,65 & 107,3 & 1,03 & 0,62 \\
P. do Chumbo & 9255 & 178,39 & 1952,8 & 45,96 & 25,49 \\
P. Andorinhas & 13087 & 251,19 & 2594,4 & 65,12 & 26,21 \\
B. do Funchal & 881 & 19,28 & 283,9 & 4,09 & 3,75 \\
Faz. B. Jardim & 1708 & 34,99 & 488,5 & 8,22 & 3,57 \\
Faz. São Félix & 905 & 19,74 & 290,2 & 4,21 & 1,54 \\
Abaeté & 466 & 11,39 & 168,4 & 2,01 & 0,68 \\
Taquaral & 623 & 14,38 & 213,6 & 2,80 & 1,10 \\
Calciolândia & 276 & 7,78 & 109,6 & 1,06 & 0,45 \\
\hline & & & & &
\end{tabular}

A titulo de verificação foram calculados as vazões: $\mathrm{Q}_{\mathrm{mlp}}, \mathrm{Q}_{7,10}, \mathrm{Q}_{95 \%}$ e $\mathrm{Q}_{50}$ utilizando o procedimento Regionalização Hidrológica I/II e comparado com as vazões estimadas no "exemplo de aplicação" (Regionalização Hidrológica II/II). Os resultados obtidos encontram-se na Tabela 18 onde estão indicados os desvios entre os valores obtidos nos dois procedimentos.

Os resultados obtidos no "exemplo de aplicação" mostram que o procedimento Regionalização Hidrológica II/II, apresentou resultados ruíns para estimativa da vazão mínima de sete dias de duração e período de retorno de 10 anos $\left(Q_{7,10}\right)$ e vazão diária com permanência de $95 \%$ (Q95\%). Já na 
Tabela 18. Comparação entre as vazões obtidas pelos dois procedimentos de regionalização hidrológica, no exemplo de aplicação.

\begin{tabular}{lrrr}
$\begin{array}{l}\text { Sub-bacia } \\
\text { Conceição }\end{array}$ & $\begin{array}{c}\text { Regionalização Regionalização } \\
\text { hidrológica } \\
\text { Itaguá }\end{array}$ & $\begin{array}{c}\text { Desvio } \\
\text { hidrológica }\end{array}$ & \multicolumn{1}{c}{$\begin{array}{c}\text { II } \%) \\
\text { II }\end{array}$} \\
\hline $\mathrm{Q}_{\mathrm{mlp}}$ & 11,38 & 11,33 & $-0,44$ \\
$\mathrm{Q}_{7,10}$ & 2,31 & 1,12 & $-106,25$ \\
$\mathrm{Q}_{95}$ & 3,20 & 2,13 & $-50,23$ \\
$\mathrm{Q}_{50}$ & 169,16 & 187,84 & $+9,94$ \\
\hline
\end{tabular}

vazão média de longo período (Qmlp) e vazão máxima diária anual com período de retorno de 50 anos os resultados foram razoavelmente precisos, podendo ser útil em avaliações preliminares. Para fins de planejamento o procedimento Regionalização Hidrológica I/II é o mais recomendado.

\section{Regionalização de curvas de regularização}

De posse dos coeficientes de melhor ajustamento, das tendências das curvas (valores de $b$ próximos) e das características climáticas das vinte e oito sub-bacias, definiram-se quatro regiões homogêneas para as curvas de regularização, as quais estão apresentadas no mapa da Figura 20.

A estação de Calciolândia foi descartada deste estudo, por apresentar valores subestimados em relação às vazões já estudadas e também tendência da curva adimensional mais diferenciada.

As curvas adimensionais selecionadas (individual e regional) para estimativa do volume de regularização, para as quatros regiões hidrológicamente homogêneas se encontram na Tabela 19.

Exemplo de aplicação - Estimar o volume necessário para garantir a demanda constante de $20 \mathrm{~m}^{3} / \mathrm{s}$, no rio Paraopeba, cujas coordenadas são $44^{\circ} 10^{\prime} \mathrm{W}$ e $19^{\circ} 45^{\prime} \mathrm{S}$.

Dados:

- Área da Bacia: 2.000 km²

- Evaporação média anual: 1.200 mm;

- Área reservatório para 2/3 do volume: $30 \mathrm{~km}^{2}$

\section{Comentários:}

1. Estime o volume sem considerar a evaporação e, a seguir, considere nos cálculos, a evaporação de forma simplificada;

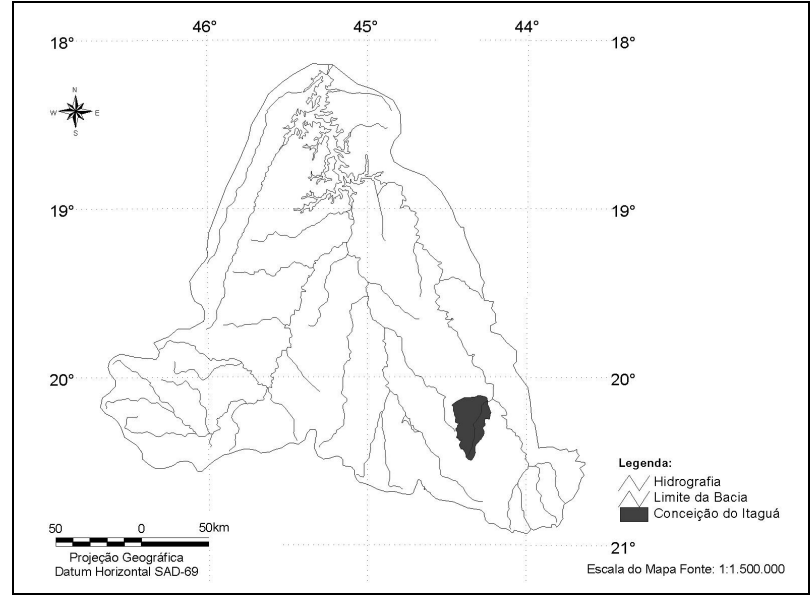

Figura 18. Localização da sub-bacia de Conceição do Itaguá no mapa da região estudada.

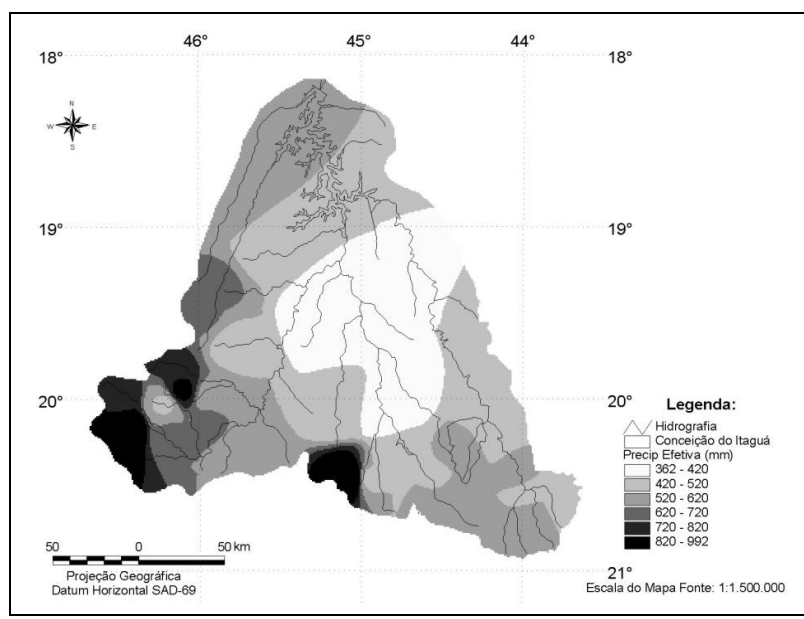

Figura 19. Precipitação efetiva média pluvial total anual espacializada na região, caracterizando a sub-bacia de Conceição do Itaguá no mapa.

2. O modelo selecionado da vazão média de longo período em $\mathrm{m}^{3} / \mathrm{s}$ para a bacia do rio Paraopeba no local de interesse foi:

$$
\begin{aligned}
& \mathrm{Q}_{\mathrm{mlp}}=0,022 . \mathrm{A}^{0,964}, \text { que resultou em } \\
& \mathrm{Q}_{\mathrm{mlp}}=33,47 \mathrm{~m}^{3} / \mathrm{s} .
\end{aligned}
$$

A) sem considerar a evaporação:

A vazão adimensional é calculada por:

$$
\mathrm{m}=\frac{\mathrm{Q}}{\mathrm{Q}_{\mathrm{mlp}}} 100=\frac{20}{33,47} 100=59,750 \%
$$

Como o local de interesse encontra-se na Região I, no quadro RH seleciona-se o modelo da 


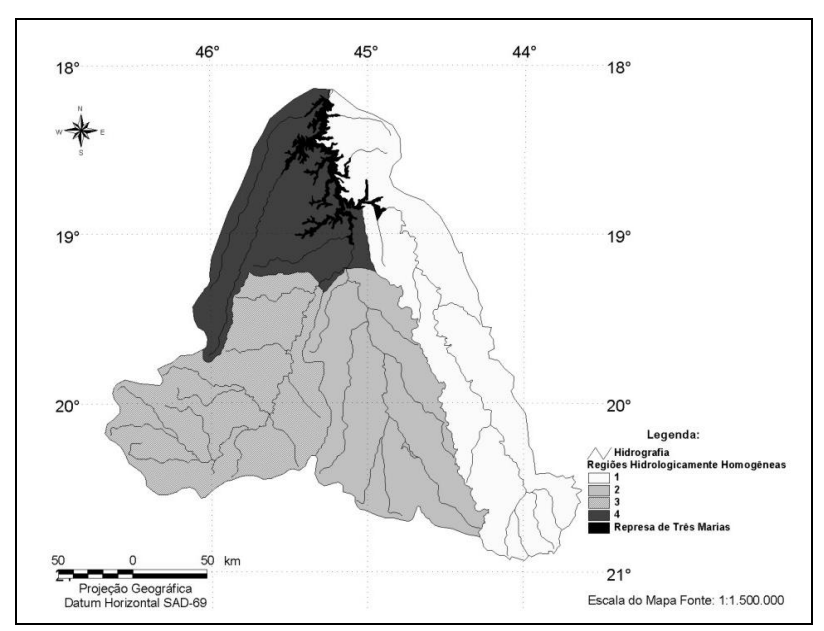

Figura 20. Regiões hidrologicamente homogêneas para as curvas de regularização.

curva regional $(a=1,6696 \mathrm{E}-7$ e $b=4,546590)$, ou seja:

$$
r=a x^{b}=1,6696 \mathrm{E}-7(59,75)^{4,546590}=19,895 \%
$$

Utilizando a Equação (18) e substituindo-se os valores, obtem-se $v=210,020.10^{6} \mathrm{~m}^{3}$

B) considerando a evaporação:

Substituindo-se os valores da evaporação, área do reservatório (2/3 do volume) e vazão média de longo período na Equação (19) (me $=0,00317 \mathrm{E} . \mathrm{A} / \mathrm{Qmlp}$ ), obtem-se me = 3,410.

A demanda adicional total, neste caso é dada pela Equação $(20)\left(m^{*}=m e+m\right)$.

Neste caso, $m^{*}=3,410+59,750$ ou seja $m^{*}=63,160$.

Substituindo novamente este valor no modelo selecionado da curva regional:

$$
r=1,6696 \mathrm{E}-7(63,160)^{4,546590}
$$

obtem-se $r=25,605 \%$.

A seguir, aplicando novamente a Equação (18), obtem-se o volume:

$$
\mathrm{v}=270,298 \cdot 10^{6} \mathrm{~m}^{3}
$$

Os resultados da impressão deste procedimento utilizando a tabela "Estimativa" do Quadro "Curva Regional" do programa RH3.0, considerando a evaporação, apresenta a listagem vista a seguir.

Finalmente, para aplicação dos resultados obtidos neste trabalho, recomendam-se:
Tabela 19. Curvas de regularização adimensionalizadas

\begin{tabular}{|c|c|c|c|}
\hline \multicolumn{4}{|c|}{ Região - I } \\
\hline Pte. N. do Paraopeba & $5,940 \mathrm{E}-10$ & 5,784 & 0,94 \\
\hline Conceição do Itaguá & $2,640 \mathrm{E}-9$ & 5,454 & 0,91 \\
\hline Usina João Ribeiro & $2,482 \mathrm{E}-8$ & 4,998 & 0,88 \\
\hline Belo Vale & $1,484 \mathrm{E}-7$ & 4,617 & 0,93 \\
\hline Alberto Flores & $1,528 \mathrm{E}-7$ & 4,585 & 0,92 \\
\hline Ponte Taquara & $1,198 \mathrm{E}-6$ & 4,208 & 0,93 \\
\hline Entre Rios de Minas & $9,665 \mathrm{E}-7$ & 4,150 & 0,93 \\
\hline Curva Regional & $1,669 \mathrm{E}-7$ & 4,546 & 0,88 \\
\hline \multicolumn{4}{|c|}{ Região - II } \\
\hline Pari & $1,231 \mathrm{E}-8$ & 5,198 & 0,93 \\
\hline Martinho Campos & $2,550 \mathrm{E}-8$ & 4,987 & 0,95 \\
\hline Jaguaruna-jusante & 9,347E-8 & 4,545 & 0,91 \\
\hline Velho da Taipa & $3,016 \mathrm{E}-7$ & 4,521 & 0,88 \\
\hline Marilândia & 2,309E-7 & 4,458 & 0,95 \\
\hline Escola Á. da Silveira & $3,608 \mathrm{E}-6$ & 3,874 & 0,94 \\
\hline Carmo do Cajuru & $1,606 \mathrm{E}-4$ & 3,095 & 0,94 \\
\hline Curva Regional & $2,629 \mathrm{E}-6$ & 3,909 & 0,85 \\
\hline \multicolumn{4}{|c|}{ Região - III } \\
\hline Tapiraí - jusante & $7,834 \mathrm{E}-12$ & 6,675 & 0,93 \\
\hline Fazenda Samburá & $1,343 \mathrm{E}-8$ & 5,020 & 0,93 \\
\hline M. do B. Sucesso & $8,265 \mathrm{E}-9$ & 5,009 & 0,86 \\
\hline Ponte do Chumbo & $3,702 \mathrm{E}-8$ & 4,923 & 0,92 \\
\hline Vargem Bonita & $5,071 \mathrm{E}-7$ & 4,820 & 0,92 \\
\hline Iguatama & $1,687 \mathrm{E}-7$ & 4,633 & 0,91 \\
\hline Fazenda Ajudas & $3,133 \mathrm{E}-7$ & 4,499 & 0,90 \\
\hline Fazenda da Barra & $4,161 \mathrm{E}-7$ & 2,296 & 0,90 \\
\hline Curva Regional & $8,832 \mathrm{E}-8$ & 4,637 & 0,84 \\
\hline \multicolumn{4}{|c|}{ Região - IV } \\
\hline Fazenda Bom Jardim & 2,097E-6 & 4,030 & 0,93 \\
\hline Barra do Funchal & 2,127E-5 & 3,520 & 0,92 \\
\hline Taquaral & $5,430 \mathrm{E}-5$ & 3,393 & 0,91 \\
\hline Fazenda São Félix & $2,728 \mathrm{E}-5$ & 3,376 & 0,92 \\
\hline Abaeté & $1,950 \mathrm{E}-4$ & 3,098 & 0,95 \\
\hline Curva Regional & $4,234 \mathrm{E}-5$ & 3,365 & 0,89 \\
\hline
\end{tabular}
selecionadas para estimativa do volume de regularização, nas quatros regiões homogêneas.

a. vazão média de longo período - os modelos apresentados na Tabela 2;

b. vazões mínimas de sete dias de duração os modelos apresentados na Tabela 5;

c. vazões máximas - os modelos apresentados na Tabela 8;

d. vazões obtidas da curva de permanência para probabilidades de 50 a $95 \%$ - os modelos apresentados na Tabela 10; 
RH - Regionalização Hidrológica

\section{REGIONALIZAÇÃO DA CURVA DE REGULARIZAÇÃO}

Observação:

Regionalização da curva de regularização para as Sub-Bacias do Rio São Francisco a montante da Barragem de Três Marias. Sete estações com série histórica de 29 anos (1964 -1992).

Região: 1

Modelo: Potencial

\begin{tabular}{lccccc}
\hline Estação & Inicio & Fim & $a$ & $b$ & $R 2$ \\
\hline P. N. Paraopeba & $11 / 1981$ & $12 / 1992$ & $5.940 E-10$ & 5.784 & 0.940 \\
Conceição Itaguá & $10 / 1965$ & $08 / 1980$ & $2.641 E-9$ & 5.454 & 0.910 \\
Usina João Ribeiro & $09 / 1971$ & $02 / 1983$ & $2.482 E-8$ & 4.998 & 0.880 \\
Belo Vale & $08 / 1965$ & $02 / 1991$ & $1.484 E-7$ & 4.617 & 0.930 \\
Alberto Flores & $04 / 1967$ & $11 / 1989$ & $1.528 E-7$ & 4.585 & 0.920 \\
Ponte Taquara & $06 / 1967$ & $12 / 1992$ & $1.198 E-6$ & 4.208 & 0.930 \\
Entre R. De Minas & $01 / 1964$ & $12 / 1989$ & $9.665 E-7$ & 4.150 & 0.930 \\
Curva Regional & & & $1.670 E-7$ & 4.547 & 0.880 \\
\hline
\end{tabular}

Estimativa do volume de regularização:

Vazão média de longo período (m3/s)......

33,47

Evaporação total média anual ( $\mathrm{mm}$ ).

1200

Área do reservatório $(\mathrm{km} 2)$

Vazão demandada $(\mathrm{m} 3 / \mathrm{s})$

Volume de regularização (Hm3) e. estimativas de volumes de regularização sequência de procedimentos apresentados no item - "Uso das curvas para estimativa do volume" e os modelos da curva regional apresentados na Tabela 19

\section{RESUMO E CONCLUSÕES}

Este trabalho descreve os estudos realizados para obtenção de metodologia para a estimativa das potencialidades e disponibilidades dos recursos hídricos em qualquer curso d'água da região do Alto São Francisco.

Assim, através da técnica da regionalização hidrológica, tornou-se possível estimar as seguintes variáveis hidrológicas:

- vazão média de longo período;

- vazão máxima diária anual com período de retorno de 2 a 500 anos;

- vazão mínima de sete dias de duração e período de retorno de 2 a 20 anos;
- curva de permanência de vazões diárias;

- curvas de regularização.

A regionalização das vazões médias, mínimas, máximas e das vazões obtidas da curva de permanência foi desenvolvida sob dois enfoques. $\mathrm{O}$ primeiro denominado Regionalização Hidrológica I/II, utilizou a metodologia segundo a qual as vazões são regionalizadas com base nas estatísticas dos resultados da aplicação da regressão múltipla das vazões com as características físicas e climáticas das sub-bacias da região em estudo. $\mathrm{O}$ segundo denominado Regionalização Hidrológica II/II, teve como objetivo avaliar as potencialidaes e disponibilidades hídricas a partir da precipitação pluvial espacializada na bacia hidrográfica.

Através da análise dos dados de 33 estações fluviométricas, situadas na bacia do rio São Francisco a montante da Barragem de Três Marias foram determinadas as vazões médias de longo período, as mínimas de sete dias de duração e períodos de retorno de 2, 5, 10, 20 anos e as vazões má- 
ximas diárias anuais com períodos de retorno de 2 , 5, 10, 20, 50, 100 e 500 anos. A precipitação média nas sub-bacias foi calculada utilizando-se o método de Thiessen.

A caracterização das regiões hidrológicamente homogêneas foi obtida por meio de critérios físicos e estatísticos, baseados no escoamento superficial, características fisiográficas, distribuição de freqüência das vazões adimensionalizadas e nos resíduos da equação de regressão da vazão média.

Foram identificadas três regiões hidrológicamente homogêneas para as vazões médias de longo período, mínimas, máximas e vazão obtida da curva de permanência para $95 \%$ de probabilidades, denominadas de Regiões I, II, III.

Na Regionalização Hidrológica I/II aplicaramse dois métodos de regionalização de vazão. O primeiro ajusta distribuições teóricas de probabilidades às séries históricas de vazões de cada estação para diferentes períodos de retorno e a seguir aplica regressão múltipla entre estas vazões e as características físicas e climáticas das sub-bacias. O segundo adimensionaliza as curvas individuais de probabilidades, com base em seu valor médio, e estabelece uma curva adimensional regional média das estações com a mesma tendência. O valor médio (das minimas e das máximas) é regionalizado em função das características físicas e climáticas das sub-bacias, através de uma equação de regressão múltipla. Por apresentar melhor ajustamento foi selecionado o método II para representar as vazões mínimas e máximas. A vazão média de longo período foi regionalizada sem se considerar o nível de risco, ou seja com base apenas nas estatísticas dos resultados da aplicação da regressão múltipla da vazão média com as características físicas e climáticas das sub-bacias em estudo.

Nas três regiões, as distribuições que apresentaram melhor ajustamento foram a log-normal a três parâmetros nos eventos mínimos e a log-normal a dois parâmetros nos eventos máximos.

Os parâmetros das distribuições foram estimados pelo método dos momentos, enquanto a eficiência do ajustamento foi testada pelo método de Kolmogorov-Smirnov.

Para vazão mínima de sete dias de duração, nas Regiões I e II, a variável área da bacia foi selecionada para os períodos de retorno de dois a 50 anos, enquanto para a Região III a área e a declividade do curso d'água principal permaneceram no modelo, para os mesmos períodos de retorno.
Para a vazão máxima diária anual, nas Regiões I e III, a área de drenagem foi a variável que melhor explicou a variação da vazão máxima, para os períodos de retorno estudados. Na Região II, para os mesmos períodos de retorno, foi incluída a declividade do curso d'água principal no modelo.

Quanto à vazão média de longo período, a área de drenagem foi a variável que explicou a variação da vazão média nas três regiões.

Comparando as vazões específicas médias de longo período, para sub-bacias com áreas em torno de $1.500 \mathrm{~km}^{2}$, encontradas nas sub-bacias dos rios Verde Grande e Pardo (Boletim Técnico $n^{\circ} 1$ ), Jequitinhonha (Boletim Técnico $n^{\circ}$ ), Paracatu (Boletim Técnico ${ }^{\circ} 4$ ), Doce (Boletim Técnico $n^{\circ} 3$ ), e São Francisco a montante da Barragem de Três Marias verificam-se, respectivamente, valores crescentes de disponibilidade hídrica. Em geral, nota-se uma distinção bastante clara entre as bacias dos rios Verde Grande e Pardo, apresentando contribuições da ordem de $3,0 \mathrm{~L} / \mathrm{s} . \mathrm{km}^{2}$, a bacia do rio Jequitinhonha $8,0 \mathrm{~L} / \mathrm{s} . \mathrm{km}^{2}$, a bacia do rio Paracatu $13,0 \mathrm{~L} / \mathrm{s} . \mathrm{km}^{2}$, a bacia do rio Doce $15,0 \mathrm{~L} / \mathrm{s} . \mathrm{km}^{2}$ e a bacia do Alto São Francisco 18 L/s.km².

Através da análise dos dados de 28 estações fluviométricas, situadas na bacia do rio São Francisco a montante da Barragem de Três Marias foram regionalizadas a curva de permanência para as probabilidades de $50 \%$ a $95 \%$ e as curvas de regularização.

Para a curva de permanência, nos modelos escolhidos de vazão com probabilidades de $50 \%$ a $95 \%$, a variável que permaneceu na regressão, nas três regiões, foi a área de drenagem.

Foi realizado uma análise comparativa entre a vazão obtida da curva de permanência para probabilidade de $95 \%$ com a vazão mínima de sete dias de duração e período de retorno de 10 anos. Os resultados mostraram que as vazões analizadas apresentaram valores próximos para pequenas bacias de drenagem (em torno de $300 \mathrm{~km}^{2}$ ), e que as vazões com probabilidades de $95 \%$ apresentaram valores superiores a vazão mínima de sete dias de duração e período de retorno de 10 anos, com o aumento das áreas das bacias.

Quanto as curvas de regularização foram identificadas quatro regiões hidrológicamente homogêneas para as estas curvas, denominadas de Região I, II, III e IV. Por meio da curva regional de cada região e da vazão média de longo período no local de interesse é possível estimar o volume necessário à regularização da vazão. 
Observando os limites das regiões hidrológicamente homogêneas, verifica-se que os modelos encontrados neste trabalho permitem, em qualquer seção dos cursos d'água da bacia do rio São Francisco a montante da Barragem de Três Marias, estimar:

a. vazões específicas mínimas de sete dias de duração, associadas aos períodos de retorno de 2, 5, 10, 20 e 50 anos;

b. vazões específicas máximas diárias anuais, associadas aos períodos de retorno de 2, 5, 10, 20, 50, 100 e 500 anos;

c. vazão específica média de longo período;

d. vazões com permanência de $50 \%$ a $95 \%$;

e. volumes para regularização de vazões.

Na regionalização Hidrológica II/II os resultados mostraram que a partir da precipitação efetiva média anual espacializada na bacia, é possível estimar a vazão média de longo período e a partir desta, estimar a vazão máxima para período de retorno de 50 anos, a vazão mínima de sete dias de duração e período de retorno de 10 anos e a vazão com permanência de $95 \%$. Os resultados obtidos mostraram que este procedimento pode ser útil em avaliações preliminares para vazão média de longo período e vazão máxima diária anual com período de retorno de 50 anos. Para fins de planejamento o procedimento Regionalização Hidrológica I/II é o mais recomendado.

A aplicação dos resultados deste trabalho permite a obtenção de informações indispensáveis ao diagnóstico e planejamento de obras hidráulicas, tais como: extravazores de pequenas barragens, canais, obras de proteção contra inundações, sistemas de drenagem, bueiros, galerias pluviais, pontes, projetos de abastecimento d'água e irrigação, estudos da qualidade da água, volume de regularização, concessão de uso da água para uma determinada finalidade, navegação, estudos hidrelétricos e outros.

\section{RECOMENDAÇÕES}

Considerando o reduzido período das séries históricas das vazões e a baixa densidade das estações fluviométricas, a aplicação dos resultados obtidos neste estudo é recomendável às etapas de diagnóstico e planejamento, não dispensando pesquisas mais minuciosas, no caso de outras finalidades.
Resalta-se aqui a necessidade de otimização da rede hidrométrica local, aumentando o número de estações e recuperando aquelas deficientes.

A metodologia, aqui empregada, resultou de uma análise realizada em bacias hidrográficas cujas áreas de contribuição variaram de 259 a $13.300 \mathrm{~km}^{2}$, para as vazões estudadas. Certa cautela é aconselhável, no caso de estimativas para bacias fora deste intervalo.

Este estudo deverá ser atualizado após alguns anos, quando as séries das estações forem mais longas.

\section{REFERÊNCIAS}

CRUFF, R. W.; RANTZ, S. E. (1965). A comparacion of methods used in flood frequency studies for coastal basins in California, s.l., USGS Water Supply (Paper 1580-E).

EUCLYDES, H. P. (1992). Regionalização de vazões máximas e mínimas para a bacia do Rio Juatuba-MG, Viçosa, UFV. Impr. Univ. p. 66 (Tese M.Sc.).

KITE, G. W. (1978). Frequency and risk analyses in hidrology. Fort Collins, Water Resources, p. 224.

LANNA, A. E. (1993). Regularização de vazões em reservatórios. In: TUCCI, C. E. M., org. Hidrologia. Porto Alegre, EDUSP, ABRH, p. 703-720 (Coleção ABRH de Recursos Hídricos, 4).

LETTEENMAIER, D. P.; BURGES, S. J. (1982). Gumbel's extreme value I distribution; anew look. Journal of the Hydraulics Division, 108:502-513.

MAIONE, U. (1977). Aponti di idrologia - le piene fluviali. Pavia, La Goliarca Pavese, p. 224.

TUCCI, C. E. M. (1993). Regionalização de vazões. In: TUCCI, C. E. M., org. Hidrologia. Porto Alegre, EDUSP, ABRH,. p. 573-611 (Coleção ABRH de Recursos Hídricos, 4). 


\title{
Hydrologic Regionalization in the Upper São \\ Francisco Basin Upstream from Três Marias Dam, State of Minas Gerais
}

\begin{abstract}
This paper describes the studies performed in order to obtain a methodology to estimate the potentials and availability of water resources in any watercourse in the Upper São Francisco region, state of Minas Gerais.

The regionalization of the mean, minimum and maximum flow rates as well as the flow rates obtained from the residence curve was developed with two approaches. The first one, called Hydrologic Regionalization I/II, used a methodology according to which the flow rates are regionalized based on the statistics of the results of applying the multiple regression of flow rates with the physical and climatic characteristics of the sub-basins in the region under study. The second approach, called Hydrologic Regionalization II/II, aimed at evaluating the potentials and water availability based on rainfall, spatialized in the river basin.

Observing the limits of the hydrologically homogeneous regions it was found that the models in this study allow an estimate in any section of the watercourses of São Francisco River Basin upstream from Três Marias dam, as follows: a) minimum specific flow rates with seven days duration, associated to the return periods of 2, 5, 10, 20 and 50 years; b) annual daily maximum specific flow rates associated to the return periods of 2, 5, 10, 20, 50, 100 and 500 years; c) average specific flow rate over long periods; d) flow rates with a residence time of $50 \%$ to $95 \%$; and e) volumes for flow rates regulation.
\end{abstract}

Key-words: regionalization; water availability; hydrologic regionalization. 